\title{
The source model and recurrence interval of Genroku-type Kanto earthquakes estimated from paleo-shoreline data
}

Toshinori Sato ${ }^{1 *}$, Harutaka Higuchi ${ }^{1}$, Takahiro Miyauchi ${ }^{1}$, Kaori Endo ${ }^{1}$, Noriko Tsumura', Tanio Ito ${ }^{2}$, Akemi Noda ${ }^{3}$ and Mitsuhiro Matsu'ura ${ }^{4}$

\begin{abstract}
In the southern Kanto region of Japan, where the Philippine Sea plate is descending at the Sagami trough, two different types of large interplate earthquakes have occurred repeatedly. The 1923 (Taisho) and 1703 (Genroku) Kanto earthquakes characterize the first and second types, respectively. A reliable source model has been obtained for the 1923 event from seismological and geodetical data, but not for the 1703 event because we have only historical records and paleo-shoreline data about it. We developed an inversion method to estimate fault slip distribution of interplate repeating earthquakes from paleo-shoreline data on the idea of crustal deformation cycles associated with subduction-zone earthquakes. By applying the inversion method to the present heights of the Genroku and Holocene marine terraces developed along the coasts of the southern Boso and Miura peninsulas, we estimated the fault slip distribution of the 1703 Genroku earthquake as follows. The source region extends along the Sagami trough from the Miura peninsula to the offing of the southern Boso peninsula, which covers the southern two thirds of the source region of the 1923 Kanto earthquake. The coseismic slip takes the maximum of $20 \mathrm{~m}$ at the southern tip of the Boso peninsula, and the moment magnitude (Mw) is calculated as 8.2. From the interseismic slip-deficit rates at the plate interface obtained by GPS data inversion, assuming that the total slip deficit is compensated by coseismic slip, we can roughly estimate the average recurrence interval as 350 years for large interplate events of any type and 1400 years for the Genroku-type events.
\end{abstract}

Keywords: Paleo-shoreline data, Earthquake cycles, Interseismic slip deficit, Genroku earthquake, Source model, Recurrence interval

\section{Background}

Beneath the southern Kanto region, central Japan, the Philippine Sea plate is descending at the Sagami trough and running on the Pacific plate at its eastern margin (e.g., Hashimoto et al. 2004) as shown in Fig. 1. The relative motion vector of the Philippine Sea plate is about $3 \mathrm{~cm} /$ year in the direction of $\mathrm{N} 60^{\circ} \mathrm{W}$ at the Sagami trough (DeMets et al. 1994). Geomorphological data show that the southern parts of the Boso and Miura peninsulas have been uplifted through Quaternary (e.g., Kaizuka 1987). A dense GNSS network (GEONET) covers the southern Kanto region since 1996. Noda et al.

\footnotetext{
* Correspondence: satot@earth.s.chiba-u.ac.jp

${ }^{1}$ Graduate School of Science, Chiba University, 1-33 Yayoi-cho, Inage-ku,

Chiba 263-8522, Japan

Full list of author information is available at the end of the article
}

(2013) estimated interseismic slip-deficit rates at the plate interface from the GPS data and revealed that a broad zone with high slip-deficit rates extends along the Sagami trough from southeast off the Boso peninsula to the Izu-Mainland collision zone.

According to Matsuda et al. (1978), two different types of large interplate earthquakes have repeatedly occurred in the southern Kanto region. The 1923 (Taisho) and 1703 (Genroku) Kanto earthquakes characterize the first and second types, respectively. Both of them are megathrust events at the same plate interface, but their source regions seem to be somewhat different because of significant difference in coseismic displacement patterns (e.g., Matsuda et al. 1978). The fault slip distribution of the 1923 Taisho event has been estimated from geodetic (triangulation and leveling) data by many researchers

\section{Springer}




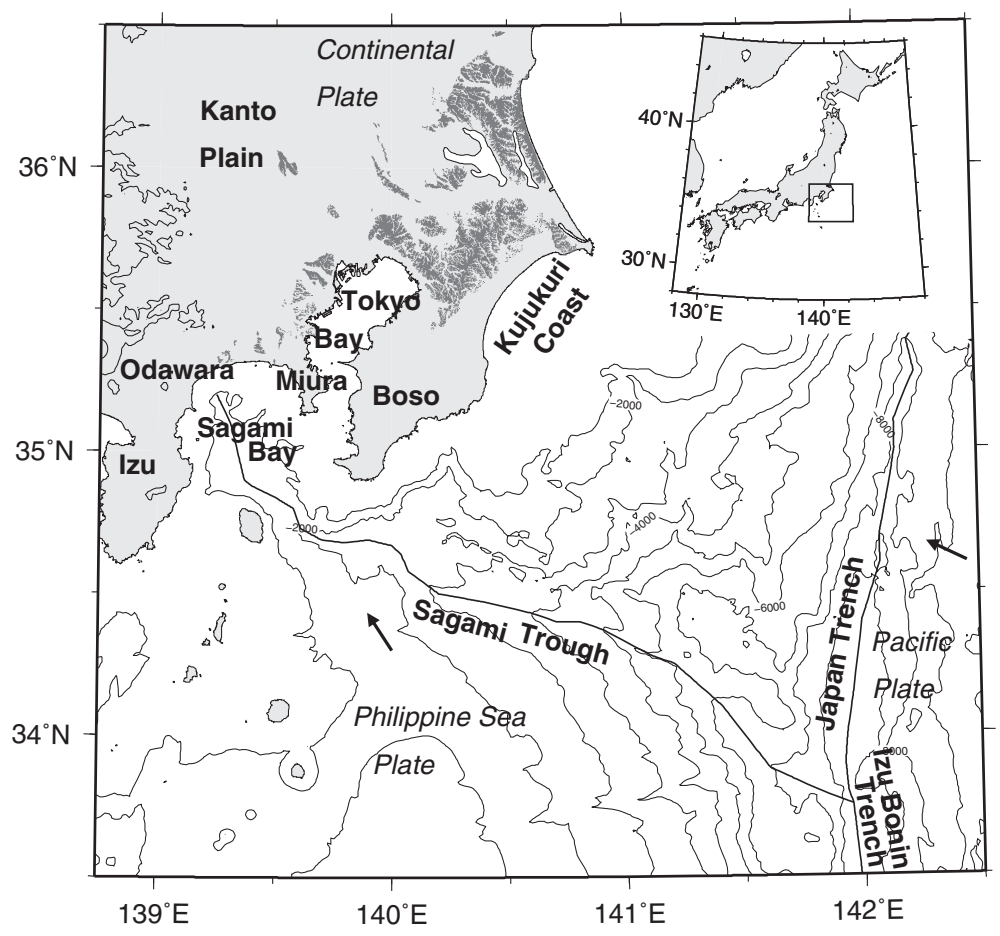

Fig. 1 Tectonic setting of the Kanto region, central Japan. The Pacific plate is descending beneath northeast Japan and the Philippine Sea plate. The Philippine Sea plate is descending beneath the Boso peninsula at the Sagami trough and running on the Pacific plate at its eastern margin. The arrows indicate the directions of plate motion relative to the Kanto region. The contours indicate bathymetry at the interval of 1000 m. Dark gray areas in land indicate the Shimosueyoshi surface formed during the last interglacial period (125 kyr BP) (Koike and Machida 2001)

(e.g., Ando 1971; Matsu'ura et al. 1980, 2007; Kobayashi and Koketsu 2005). According to Matsu'ura et al. (2007), the fault slip distribution along the Sagami trough is bimodal; an 8-m peak beneath Odawara and a 10-m peak beneath the Miura peninsula. On the other hand, from historical records and paleo-shoreline data, the 1703 Genroku event is conceived to be larger than the 1923 Taisho event (M7.9), but its source model is still controversial.

Along the coasts of the southern Boso peninsula, a series of well-developed Holocene marine terraces, called the Numa I-IV terraces, are observed (e.g., Nakata et al. 1980). The lowest one (Numa IV) is the abrasion platform emerged at the time of the 1703 Genroku earthquake (e.g., Imamura 1925; Matsuda et al. 1978). From the present heights of these marine terraces, many researchers (e.g., Matsuda et al. 1978; Shimazaki and Nakata 1980; Shishikura 2003; Namegaya et al. 2011) have estimated the source model and/or recurrence interval of the 1703 Genroku event. In these studies, however, the following two points seem to be unreasonable.

The first point is about the deformation cycles associated with subduction-zone earthquakes. The occurrence of an interplate earthquake is generally regarded as the sudden fault slip that releases the shear stress caused by interseismic slip deficit in a source region. After the coseismic slip, the source region is stuck soon, but the remaining part of the plate interface goes on slipping aseismically through the interseismic period. Matsu'ura and Sato (1989) modeled the crustal deformation cycle associated with such a process on the basis of elastic dislocation theory. The results of their numerical simulation demonstrate that coseismic vertical displacements gradually tend to permanent displacements due to steady plate subduction with time because of the viscoelastic stress relaxation in the asthenosphere and the increase of slip deficits in the source region. So far, to estimate coseismic vertical displacements from the present heights of the Genroku terrace, it has been assumed that the rates of vertical motion during the interseismic period are constant in time and space. However, this assumption is not correct; the recovery rates (even their signs) gradually change with time in the interseismic period and vary place by place (e.g., Thatcher 1984; Fukahata et al. 1996).

The second point is about the origin of the Holocene marine terraces. So far, from the similarity in the present height pattern and wider surface feature between the Numa IV (Genroku) terrace and the others, it has been believed that the Numa I-III terraces also emerged by the occurrence of past Genroku-type events. However, as demonstrated by Matsu'ura and Sato (1989), the 
coseismic vertical displacement pattern gradually fades out with time, and after the completion of one earthquake cycle, only a permanent displacement due to steady plate subduction remains (see Figures 4 and 5 in Matsu'ura and Sato (1989)). In addition, we cannot deny the possibility that the Numa I-III terraces have been formed by Holocene sea-level fluctuation (e.g., Umitsu 1991; Siddall et al. 2003), because marine terraces can be formed by small sea-level fluctuation if the steady uplift rate of land is very fast like the southern Boso peninsula (e.g., Kaizuka 1987; Hashimoto et al. 2004). Above all, without regard to the origin of marine terraces, some of them might have been removed by sea-level fluctuation. So, it would not be a reliable way to estimate the recurrence interval of the Genroku-type events from the difference in age between adjoining terraces.

In the next section, we develop an inversion method to estimate fault slip distribution of interplate large earthquakes from paleo-shoreline data on the idea of deformation cycles associated with subduction-zone earthquakes. Then, applying the inversion method to the present heights of the Genroku and Holocene marine terraces developed along the coasts of the southern Boso and Miura peninsulas, we estimate the fault slip distribution of the 1703 Genroku earthquake.

\section{Methods}

\section{Mathematical formulation}

We consider vertical motion of the earth's surface due to the periodic occurrence of two different types (Taisho and Genroku types) of earthquakes at a plate interface $\Sigma$, which cuts an elastic surface layer (lithosphere) overlying a Maxwell-type viscoelastic substratum (asthenosphere) under gravity (Fig. 2). For simplicity, we assume that these large interplate events occur periodically and Genrokutype events occur once every $n$ large interplate events; that is, denoting the recurrence interval of the large interplate events in the southern Kanto region as $T$, the average recurrence intervals of Taisho- and Genroku-type events are given by $T_{T}=n T /(n-1)$ and $T_{G}=n T$, respectively. We suppose that the periodic occurrence of these earthquakes started at a time $t=0$. From Matsu'ura and Sato (1989) and Matsu'ura et al. (2007), the vertical surface displacements $z(\mathbf{x}, t)$ due to fault slip is generally written as

$$
z(\mathbf{x}, t)=\int_{0}^{t} d \tau \int_{\Sigma}\left\{q_{1}(\mathbf{x}, t-\tau ; \boldsymbol{\xi}, 0) \dot{w}_{1}(\boldsymbol{\xi}, \tau)+q_{2}(\mathbf{x}, t-\tau ; \boldsymbol{\xi}, 0) \dot{w}_{2}(\boldsymbol{\xi}, \tau)\right\} d \boldsymbol{\xi} t \geq 0
$$

Here, $w_{1(2)}(\boldsymbol{\xi}, \tau)$ denotes fault slip components at a point $\boldsymbol{\xi}$ and a time $\tau$ parallel (1) and perpendicular (2) to relative plate motion and the dot indicates time derivative. The integral kernel $q_{1(2)}(\mathbf{x}, t-\tau ; \boldsymbol{\xi}, 0)$ denotes the quasistatic vertical displacement response at a point $\mathbf{x}$ and a time $t$ for the unit step increase of $w_{1(2)}(\boldsymbol{\xi}, \tau)$.

We divide the plate interface $\Sigma$ into a seismogenic region $\Sigma_{s}$ and the remaining steady-slip region $\Sigma-\Sigma_{s}$. The fault slip vector $\mathbf{w}=\left(w_{1}, w_{2}\right)$ in the seismogenic region can be represented by the superposition of steady slip at the rate of relative plate motion $\mathbf{V}_{p l}=\left(V_{p l}, 0\right)$ and its perturbation $\mathbf{w}_{s}$;

$$
\mathbf{w}(\boldsymbol{\xi}, t)= \begin{cases}\mathbf{V}_{p l}(\boldsymbol{\xi}) t+\mathbf{w}_{s}(\boldsymbol{\xi}, t) & \text { on } \Sigma_{s} \\ \mathbf{V}_{p l}(\boldsymbol{\xi}) t & \text { on } \Sigma-\Sigma_{s}\end{cases}
$$

In the present case, we denote the seismogenic regions of the Genroku- and Taisho-type events by $\Sigma_{G}$ and $\Sigma_{T}$, respectively, and the recurrence intervals of them by $T_{G}$ and $T_{T}$, respectively. Then, the slip perturbation in each segment, $\mathbf{w}_{G}(\boldsymbol{\xi}, t)$ in $\Sigma_{G}$ or $\mathbf{w}_{T}(\boldsymbol{\xi}, t)$ in $\Sigma_{T}$, can be written as

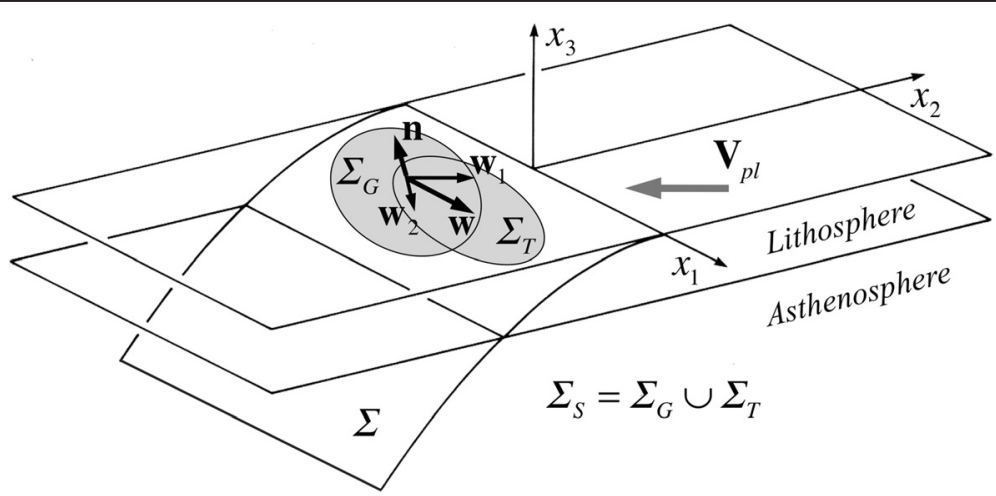

Fig. 2 Schematic representations of plate interface and source regions. A plate interface $\Sigma$ cuts an elastic surface layer (lithosphere) overlying a Maxwell-type viscoelastic substratum (asthenosphere) under gravity. The shaded areas, $\Sigma_{T}$ and $\Sigma_{G}$ on the plate interface denote the source regions for the Genroku- and Taisho-type earthquakes, respectively. The slip vector $\mathbf{w}$ on the plate interface with a unit normal vector $\mathbf{n}$ is decomposed into the parallel $\left(\mathbf{w}_{1}\right)$ and perpendicular $\left(\mathbf{w}_{2}\right)$ components to the direction of plate motion $\left(\mathbf{V}_{p}\right)$ 


$$
\left\{\begin{aligned}
\mathbf{w}_{G}(\boldsymbol{\xi}, t) & =-\mathbf{f}_{G}(\boldsymbol{\xi})\left[\frac{t}{T_{G}}-\sum_{k=1}^{n_{G}} H\left(t-t_{k}^{G}\right)\right] & t_{k+1}^{G}>t \geq 0 & \text { on } \Sigma_{G} \\
\mathbf{w}_{T}(\boldsymbol{\xi}, t) & =-\mathbf{f}_{T}(\boldsymbol{\xi})\left[\frac{t}{T_{T}}-\sum_{k=1}^{n_{T}} H\left(t-t_{k}^{T}\right)\right] & t_{k+1}^{T}>t \geq 0 & \text { on } \Sigma_{T}
\end{aligned}\right.
$$

Here, $\mathbf{f}_{G(T)}(\boldsymbol{\xi})$ denotes the coseismic slip vector at a point $\boldsymbol{\xi}$ for the Genroku (Taisho)-type events, $t_{k}^{G(T)}$ the time of the $k$ th Genroku (Taisho)-type event, and $n_{G(T)}$ the number of times of the latest Genroku (Taisho)-type event. $H(\mathrm{t})$ indicates the Heaviside step function. Substituting Eqs. (2) and (3) into Eq. (1), we obtain

$$
\begin{aligned}
z(\mathbf{x}, t)= & \int_{0}^{t} U_{s}(\mathbf{x}, t-\tau) d \tau-\frac{1}{T_{G}} \int_{0}^{t} U_{G}(\mathbf{x}, t-\tau) d \tau-\frac{1}{T_{T}} \int_{0}^{t} U_{T}(\mathbf{x}, t-\tau) d \tau \\
& +\sum_{k=1}^{n_{G}} U_{G}\left(\mathbf{x}, t-t_{k}^{G}\right)+\sum_{k=1}^{n_{T}} U_{T}\left(\mathbf{x}, t-t_{k}^{T}\right) \\
& \max \left(t_{n_{G}}^{G}, t_{n_{T}}^{T}\right) \leq t<\min \left(t_{n_{G}+1}^{G}, t_{n_{T}+1}^{T}\right)
\end{aligned}
$$

with

$$
\begin{aligned}
& U_{s}(\mathbf{x}, t) \equiv \int_{\Sigma} q_{1}(\mathbf{x}, t ; \boldsymbol{\xi}, 0) V_{p l}(\boldsymbol{\xi}) d \boldsymbol{\xi} \\
& U_{G(T)}(\mathbf{x}, t) \equiv \int_{\Sigma_{G(T)}}\left\{q_{1}(\mathbf{x}, t ; \boldsymbol{\xi}, 0) f_{G(T) 1}(\boldsymbol{\xi})+q_{2}(\mathbf{x}, t ; \boldsymbol{\xi}, 0) f_{G(T) 2}(\boldsymbol{\xi})\right\} d \boldsymbol{\xi}
\end{aligned}
$$

The first term on the right side of Eq. (4) represents permanent displacements due to steady slip at $V_{p l}(\boldsymbol{\xi})$ over the whole plate interface. The second and third terms are displacements due to steady slip deficit in source regions. The fourth and fifth terms are the effects of past events, which include coseismic displacements and postseismic transient displacements due to viscoelastic stress relaxation in the asthenosphere.

The height of the 1703 Genroku paleo-shoreline is given by the difference between the vertical displacements in Eq. (4) at the present and just before the 1703 Genroku event $\left(t=t_{n_{G}}^{G-}\right)$;

$$
\Delta z(\mathbf{x}, t)=z(\mathbf{x}, t)-z\left(\mathbf{x}, t_{n_{G}}^{G-}\right)
$$

The intrinsic stress relaxation time is calculated as about 5 years for a typical value of viscosity $\left(5 \times 10^{18} \mathrm{~Pa} \mathrm{~s}\right)$ of the earth's asthenosphere (e.g., Matsu'ura and Iwasaki 1983), but it takes more than a hundred years for the complete decay of the transient vertical motion of the lithosphere-asthenosphere system (Sato and Matsu'ura 1988). The recurrence interval of large interplate earthquakes at the Sagami trough is several hundred years, and the pre-1703 large interplate earthquake occurred in
1293 (e.g., Shimazaki et al. 2011). So, replacing the viscoelastic response functions in Eqs. (5) and (6) for $t>300$ year with their values at $t=\infty$, we can finally obtain a simple equation to analyze paleo-shoreline data as

$$
\begin{aligned}
\Delta z(\mathbf{x}, t)= & \left(t-t_{n_{G}}^{G}\right) U_{s}(\mathbf{x}, \infty)-\left(t-t_{n_{G}}^{G}\right) U_{G}(\mathbf{x}, \infty) / T_{G}-\left(t-t_{n_{G}}^{G}\right) U_{T}(\mathbf{x}, \infty) / T_{T} \\
& +U_{G}\left(\mathbf{x}, t-t_{n_{G}}^{G}\right)+U_{T}\left(\mathbf{x}, t-t_{n_{T}}^{T}\right) \\
& \max \left(t_{n_{G}}^{G}, t_{n_{T}}^{T}\right) \leq t<\min \left(t_{n_{G}+1}^{G}, t_{n_{T}+1}^{T}\right)
\end{aligned}
$$

In the above equation, the first term on the right side, the permanent displacements due to steady plate subduction, should be determined from the heights of older paleo-shorelines. We can calculate the third and fifth terms, because coseismic slip distribution $\mathbf{f}_{T}(\boldsymbol{\xi})$ of the 1923 Taisho event has been already obtained from geodetic data. Then, given the present heights of the 1703 Genroku paleo-shoreline $\Delta z(\mathbf{x}, t)$, we can estimate coseismic slip distribution $\mathbf{f}_{G}(\boldsymbol{\xi})$ of the 1703 Genroku event from Eq. (8).

\section{Inversion algorithm}

In order to discretize the problem, following Yabuki and Matsu'ura (1992), we represent the spatial distribution of each slip-vector component $f_{G 1(2)}(\boldsymbol{\xi})$ by the superposition of a finite number of known basis functions $\Phi_{j}(\boldsymbol{\xi})$ as

$$
f_{G 1(2)}(\boldsymbol{\xi}) d \boldsymbol{\xi}=\frac{1}{n_{3}(\boldsymbol{\xi})} \sum_{j=1}^{m} a_{1(2) j} \Phi_{j}(\boldsymbol{\xi}) d \boldsymbol{\xi}
$$

where $n_{3}$ denotes the vertical component of normal vector of the plate interface $\Sigma$ and $m$ is the number of basis functions. Substituting Eq. (9) into Eq. (8), we obtain a linear observation equation in vector form to be solved for the coefficients $a_{1(2) j}$;

$$
\mathbf{d}=\mathbf{H a}+\mathbf{e}
$$

Here, $\mathbf{d}$ is a $N \times 1$ data vector defined as

$$
\begin{aligned}
d_{i}= & \Delta z\left(\mathbf{x}_{i}, t\right)-\left(t-t_{n_{G}}^{G}\right) U_{s}\left(\mathbf{x}_{i}, \infty\right) \\
& +\frac{\left(t-t_{n_{G}}^{G}\right)}{T_{T}} U_{T}\left(\mathbf{x}_{i}, \infty\right)-U_{T}\left(\mathbf{x}_{i}, t-t_{n_{T}}^{T}\right)
\end{aligned}
$$

where $\mathbf{e}$ is a $N \times 1$ error vector, $\mathbf{a}$ is a $2 m \times 1$ model parameter vector composed of $\mathbf{a}_{1}$ with the elements $a_{1 j}(j=1, \ldots, m)$ and $\mathbf{a}_{2}$ with the elements $a_{2 j}(j=1, \ldots$, $m)$, and $\mathbf{H}=\left[\mathbf{H}_{1}, \mathbf{H}_{2}\right]$ is a $N \times 2 m$ matrix whose elements are numerically calculated from 


$$
H_{1(2) i j}=\int_{\Sigma} \frac{1}{n_{3}(\boldsymbol{\xi})} \Phi_{j}(\boldsymbol{\xi})\left\{q_{1(2)}\left(\mathbf{x}_{i}, t-t_{n_{G}}^{G} ; \boldsymbol{\xi}, 0\right)-\frac{\left(t-t_{n_{G}}^{G}\right)}{T_{G}} q_{1(2)}\left(\mathbf{x}_{i}, \infty ; \boldsymbol{\xi}, 0\right)\right\} d \boldsymbol{\xi}
$$

From Eq. (10), assuming the errors e to be Gaussian with zero mean and a covariance matrix $\sigma^{2} \mathbf{I}$, we obtain a stochastic model that relates the data $\mathbf{d}$ with the model parameters a as

$$
p\left(\mathbf{d} \mid \mathbf{a} ; \sigma^{2}\right)=\left(2 \pi \sigma^{2}\right)^{-N / 2} \exp \left[-\frac{1}{2 \sigma^{2}}(\mathbf{d}-\mathbf{H a})^{T}(\mathbf{d}-\mathbf{H a})\right]
$$

Here, $\sigma^{2}$ is an unknown scale factor of the covariance matrix.

We usually have some prior information about the model parameters a. In the present case, we use the following two different types of prior information. One is that a roughness of fault slip distribution should be small, and the other is that the most likely direction of slip vectors is parallel to relative plate motion. Then, from Eq. (51) in Matsu'ura et al. (2007), the total prior information can be written as

$$
\begin{aligned}
p_{p}\left(\mathbf{a} ; \rho^{2}, \varepsilon^{2}\right)= & (2 \pi)^{-m}\left|\rho^{-2} \mathbf{G}+\varepsilon^{-2} \mathbf{F}^{-1}\right|^{1 / 2} \\
& \times \exp \left[-\frac{1}{2} \mathbf{a}^{T}\left(\rho^{-2} \mathbf{G}+\varepsilon^{-2} \mathbf{F}^{-1}\right) \mathbf{a}\right]
\end{aligned}
$$

with

$$
\rho^{-2} \mathbf{G}+\varepsilon^{-2} \mathbf{F}^{-1}=\left[\begin{array}{cc}
\rho^{-2} \mathbf{G}^{P} & 0 \\
0 & \rho^{-2} \mathbf{G}^{S}+\varepsilon^{-2} \mathbf{I}
\end{array}\right]
$$

where $\rho^{2}$ and $\varepsilon^{2}$ are unknown scale factors, $\mathbf{G}^{P}$ and $\mathbf{G}^{S}$ are the $m \times m$ symmetric matrices defined by Eq. (23) in Matsu'ura et al. (2007). We obtain a Bayesian model by combining the total prior information, Eq. (14), with the stochastic model, Eq. (13);

$$
p\left(\mathbf{a} ; \sigma^{2}, \alpha^{2}, \beta^{2} \mid \mathbf{d}\right)=c\left(2 \pi \sigma^{2}\right)^{-(m+N / 2)}\left|\alpha^{2} \mathbf{G}+\beta^{2} \mathbf{F}^{-1}\right|^{1 / 2} \exp \left[-\frac{1}{2 \sigma^{2}} s(\mathbf{a})\right]
$$

with

$$
s(\mathbf{a})=(\mathbf{d}-\mathbf{H a})^{T}(\mathbf{d}-\mathbf{H a})+\mathbf{a}^{T}\left(\alpha^{2} \mathbf{G}+\beta^{2} \mathbf{F}^{-1}\right) \mathbf{a}
$$

Here, $\alpha^{2} \equiv \sigma^{2} / \rho^{2}$ and $\beta^{2} \equiv \sigma^{2} / \varepsilon^{2}$ are hyper-parameters that control the relative weights of the first- and second-type prior information to the observed data.

To obtain the optimum solution, which maximizes $p\left(\mathbf{a} ; \sigma^{2}, \alpha^{2}, \beta^{2} \mid \mathbf{d}\right)$ in Eq. (16), we need to determine the optimum values of $\alpha^{2}$ and $\beta^{2}$. For this purpose, we can use Akaike's Bayesian Information Criterion (ABIC)
(Akaike 1980). Matsu'ura et al. (2007) give the explicit expression of $\mathrm{ABIC}$ as

$$
\begin{aligned}
\operatorname{ABIC}\left(\alpha^{2}, \beta^{2} \mid \mathbf{d}\right)= & N \log s\left(\mathbf{a}^{*}\right)-\log \left|\alpha^{2} \mathbf{G}+\beta^{2} \mathbf{F}^{-1}\right| \\
& +\log \left|\mathbf{H}^{T} \mathbf{H}+\alpha^{2} \mathbf{G}+\beta^{2} \mathbf{F}^{-1}\right|+C^{\prime}
\end{aligned}
$$

with

$$
\mathbf{a}^{*}=\left(\mathbf{H}^{T} \mathbf{H}+\alpha^{2} \mathbf{G}+\beta^{2} \mathbf{F}^{-1}\right)^{-1} \mathbf{H}^{T} \mathbf{d}
$$

where $C^{\prime}$ is a term independent of $\alpha^{2}$ and $\beta^{2}$. The values of $\alpha^{2}$ and $\beta^{2}$ that minimize ABIC can be found by numerical search in the 2D hyper-parameter space. Denoting the optimum values of $\alpha^{2}$ and $\beta^{2}$ by $\hat{\alpha}^{2}$ and $\hat{\beta}^{2}$, respectively, we can obtain the optimum solution $\hat{\mathbf{a}}$ and the covariance matrix $\mathbf{C}(\hat{\mathbf{a}})$ of estimation errors as

$$
\begin{aligned}
& \hat{\mathbf{a}}=\left(\mathbf{H}^{T} \mathbf{H}+\hat{\alpha}^{2} \mathbf{G}+\hat{\beta}^{2} \mathbf{F}^{-1}\right)^{-1} \mathbf{H}^{T} \mathbf{d} \\
& \mathbf{C}(\hat{\mathbf{a}})=\hat{\sigma}^{2}\left(\mathbf{H}^{T} \mathbf{H}+\hat{\alpha}^{2} \mathbf{G}+\hat{\beta}^{2} \mathbf{F}^{-1}\right)^{-1}
\end{aligned}
$$

with

$$
\hat{\sigma}^{2}=s(\hat{\mathbf{a}}) / N
$$

\section{Results}

Data used for inversion analysis

Before solving the inverse problem in Eq. (10), we need to evaluate each term in Eq. (11), that is, (1) the present heights of the Genroku terrace, (2) the effect of steady plate subduction, (3) the effect of steady slip deficit in the source region of the 1923 Taisho event, and (4) the effect of fault slip at the 1923 Taisho event. For the first term, we use the data set (locations and heights) collected by Shishikura (2000b, 2001) and Shishikura and Echigo (2001), which are shown in Fig. 3. They identified the benches emerged at the 1703 Genroku event by fossils, notches, and sea caves and measured their present heights with the maximum error of about $1 \mathrm{~m}$. They confirmed the age of the emerged benches by historical records (documents and maps) and $\mathrm{C}^{14}$ dating. Given the fault slip distribution at the 1923 Taisho event (Matsu'ura et al. 2007), we can compute the third and fourth terms. Then, the remaining problem is how to evaluate the second term.

The Shimosueyoshi surface, which is a terrace of marine origin formed during the last interglacial stage (125 kyr BP), is widely distributed in the Kanto region as shown in Fig. 1 (e.g., Kaizuka 1987; Koike and Machida 2001), but not observed in the southern Boso and Miura peninsulas because of rapid land uplift and surface erosion there (e.g., Kaizuka 1987). Instead, along the coasts 

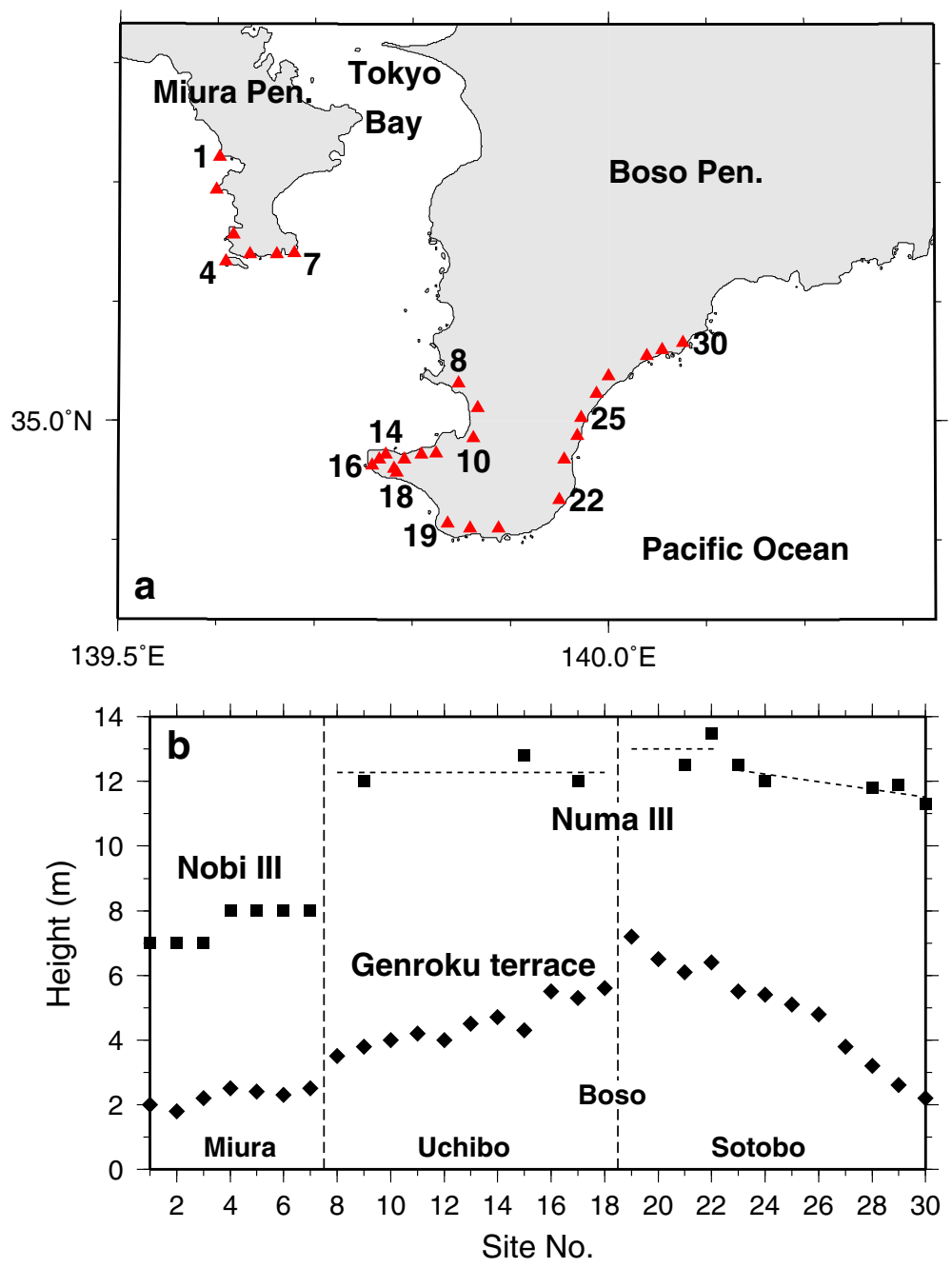

Fig. 3 Observed heights of paleo-shorelines in the Boso and Miura peninsulas. a Map of observation sites. Triangles indicate observation sites; no. 1 to 7 are in the Miura area, no. 8 to 18 are in the Uchibo area (the Tokyo Bay side of the Boso peninsula), and no. 19 to 30 are in the Sotobo area (the Pacific Ocean side of the Boso peninsula). The locations of the Genroku shoreline and the Numa III (or Nobi III) shoreline are slightly different, but almost the same in this figure scale. $\mathbf{b}$ Observed heights of paleo-shorelines. The solid diamonds and squares indicate the heights of the Genroku shoreline and the Numa III and Nobi III shorelines formed at about 3 kyr BP, respectively. The broken lines indicate the average for the Uchibo area (site no. 8-18) and the southernmost Boso area (site no. 19-22) and the linear trend for the southeast Boso area (site no. 23-30). The data are based on Shishikura (2000b, 2001) and Shishikura and Echigo (2001) for the Genroku shoreline, Nakata et al. (1980) and Shishikura (2000a) for the Numa III shoreline, and Kumaki (1982) for the Nobi IIl shoreline

of the southern Boso and Miura peninsulas, we can observe a series of Holocene marine terraces formed after the last glacial stage (e.g., Nakata et al. 1980). The four well-developed Holocene marine terraces in the southern Boso peninsula are named the Numa I-IV terraces in order of the present height. The lowest one (Numa IV) is the terrace emerged at the time of the 1703 Genroku earthquake and so-called the Genroku terrace (e.g., Imamura 1925; Matsuda et al. 1978). In the Miura peninsula, we can identify the terraces corresponding to the Numa I-III terraces, which are named the Nobi I-
III terraces in order of the present height (e.g., Kumaki 1982), but not the Genroku terrace.

For these paleo-shoreline data, most researchers have believed that higher terraces are always older. If it is true, we can easily estimate long-term steady uplift rates of land, $U_{s}\left(\mathbf{x}_{i}, \infty\right)$ in Eq. (11), from the altitudes and age (7 kyr BP) of the highest terraces. Recently, Endo and Miyauchi (2011) re-examined the altitudes and ages of Holocene emerged coastal topography in the southern Boso peninsula and found seven large steps in the Uchibo (the Tokyo Bay side of the Boso peninsula) area 
and five large steps in the Sotobo (the Pacific Ocean side of the Boso peninsula) area. An important fact is that some dating samples indicate reverse ages; that is, higher terraces are not always older. According to the preliminary results of numerical simulation for marine terrace development (Noda et al. 2015), the order in altitude of emerged marine terraces irregularly change with time, depending on the log-term uplift rates of land and the amplitudes of sea-level fluctuation.

Under the consideration mentioned above, we choose the Numa III and Nobi III terraces, formed about $3 \mathrm{kyr}$ $\mathrm{BP}$, to estimate the steady uplift rates of land. The Numa III and Nobi III terraces are better in continuity and dating than the other older terraces. In Fig. 3, we show the present heights of the Numa III and Nobi III terraces by solid squares; the data sources are Nakata et al. (1980) and Shishikura (2000a) for Numa III and Kumaki (1982) for Nobi III. The Numa III data are missing at some points, and so we took the average for the Uchibo (site no. 8-18) and the southernmost Boso (site no. 19-22) and the linear trend for the southeast Boso (site no. 2330). Given the present heights $\Delta z\left(\mathbf{x}_{i}\right)_{\text {present }}$ of the Numa III and Nobi III terraces, we can calculate the steady uplift rates of land as

$$
U_{s}\left(\mathbf{x}_{i}, \infty\right)=\left(\Delta z\left(\mathbf{x}_{i}\right)_{\text {present }}-M S L_{3 \text { kyr BP }}\right) / 3000
$$

Here, $M S L_{3 \mathrm{kyr} \text { BP }}$ represents the mean sea level at $3 \mathrm{kyr}$ BP relative to the present. Umitsu (1991) has compared diverse Holocene sea-level curves in Japan obtained by various researchers in his review paper and summarized as follows: Since the culmination of the Holocene transgression in 6500-5500 years BP, the sea level has shown minor oscillations in several regions. In the present analysis, for simplicity, we took $M S L_{3 \mathrm{kyr} \text { Вр }}$ to be zero.

\section{Coseismic slip distribution of the 1703 Genroku event}

We modeled the lithosphere-asthenosphere system by an elastic-viscoelastic two-layered half-space under gravity (Fig. 2). The structural parameters are listed in Table 1. Figure 4 shows the isodepth contours of the upper boundary surface of the descending Philippine Sea plate, which are slightly modified from the CAMP model (Hashimoto et al. 2004) by adding a small-scale bump near the tip of the Boso peninsula found by Tsumura et al. (2009). The spatial distribution of each slip-vector component $f_{G 1(2)}(\boldsymbol{\xi})$ on the plate interface is represented by the superposition of 129 normalized bi-cubic Bsplines at $8-\mathrm{km}$ intervals. The model region is shaded in Fig. 4.

Since the height data of the Genroku terrace come from the articles published in 2000 and 2001, we set the present time $t$ in Eq. (8) to be 1998; that is,
Table 1 Structural parameters used in calculations

\begin{tabular}{llccll}
\hline & $\mathrm{h}(\mathrm{km})$ & $V_{p}(\mathrm{~km} / \mathrm{s})$ & $V_{s}(\mathrm{~km} / \mathrm{s})$ & $\rho\left(\mathrm{kg} / \mathrm{m}^{3}\right)$ & $\eta(\mathrm{Pa} \mathrm{s})$ \\
\hline Lithosphere & 40 & 6.32 & 3.65 & 3000 & $\infty$ \\
Asthenosphere & $\infty$ & 7.86 & 4.20 & 3400 & $5 \times 10^{18}$
\end{tabular}

$h$ thickness of layer, $V p P$ wave velocity, $V s S$ wave velocity, $\rho$ density, $\eta$ viscosity

$$
\begin{aligned}
\Delta z\left(\mathbf{x}_{i}, 1998\right)= & 295 U_{s}\left(\mathbf{x}_{i}, \infty\right)-\frac{295}{T_{G}} U_{G}\left(\mathbf{x}_{i}, \infty\right)-\frac{295}{T_{T}} U_{T}\left(\mathbf{x}_{i}, \infty\right) \\
& +U_{G}\left(\mathbf{x}_{i}, 295\right)+U_{T}\left(\mathbf{x}_{i}, 75\right)
\end{aligned}
$$

In the present analysis, $T_{T}$ and $T_{G}$ are adjustable parameters, defined as $T_{G}=n T$ and $T_{T}=n T /(n-1)$. The recurrence interval $T$ of large interplate events of any type in the southern Kanto region is roughly estimated as 300400 years from the ages of sequentially emerged beach ridges in the Iwai Lowland (Shishikura 2003) and the catalog of historical earthquakes (e.g., Utsu 1999). So, we consider three cases of $T=300,350$, and 400 years. For the number $n$, which means that the Genroku-type events occur once every $n$ large interplate events, we search its appropriate value in the range of 2-7.

The estimated fault slip patterns are not widely different from one another, but the slip amounts are significantly different; shorter $T$ and smaller $n$ give larger slip amount. So, to determine the appropriate values of $T$ and $n$, we performed two kinds of screening test. Given certain values of $T$ and $n$, we can calculate interseismic slip-deficit rates from the estimated slip amounts $S_{G}(\mathbf{x})$ of the 1703 Genroku event and the known slip amount $S_{T}(\mathbf{x})$ of the 1923 Taisho event as

$$
R_{d}(\mathbf{x})=\frac{1}{n T} S_{G}(\mathbf{x})+\frac{(n-1)}{n T} S_{T}(\mathbf{x})
$$

The first screening test is the comparison of the calculated slip-deficit rates $R_{d}$ with the long-term subduction rate calculated from a global plate motion model (DeMets et al. 1994) and the interseismic slip-deficit rates estimated from GPS data (Noda et al. 2013). We show the results in Table 2 for two representative points on the plate interface, located just beneath site no. 1 (the Miura area) and site no. 16 (the southernmost Boso area), where the slip amounts $S_{G}$ of the 1703 Genroku event and the slip-deficit rates $R_{d}$ are given together with estimation errors (standard deviations). At these points, the long-term subduction rate is about $2.7 \mathrm{~cm} /$ year, and the interplate coupling is almost perfect. If the calculated slip-deficit rates are much larger than the long-term subduction rate, we should exclude such a case from the list of reasonable models.

As the second screening test, we compare the calculated subsidence rates with the geodetically observed interseismic subsidence rates. From tide-gauge data for 


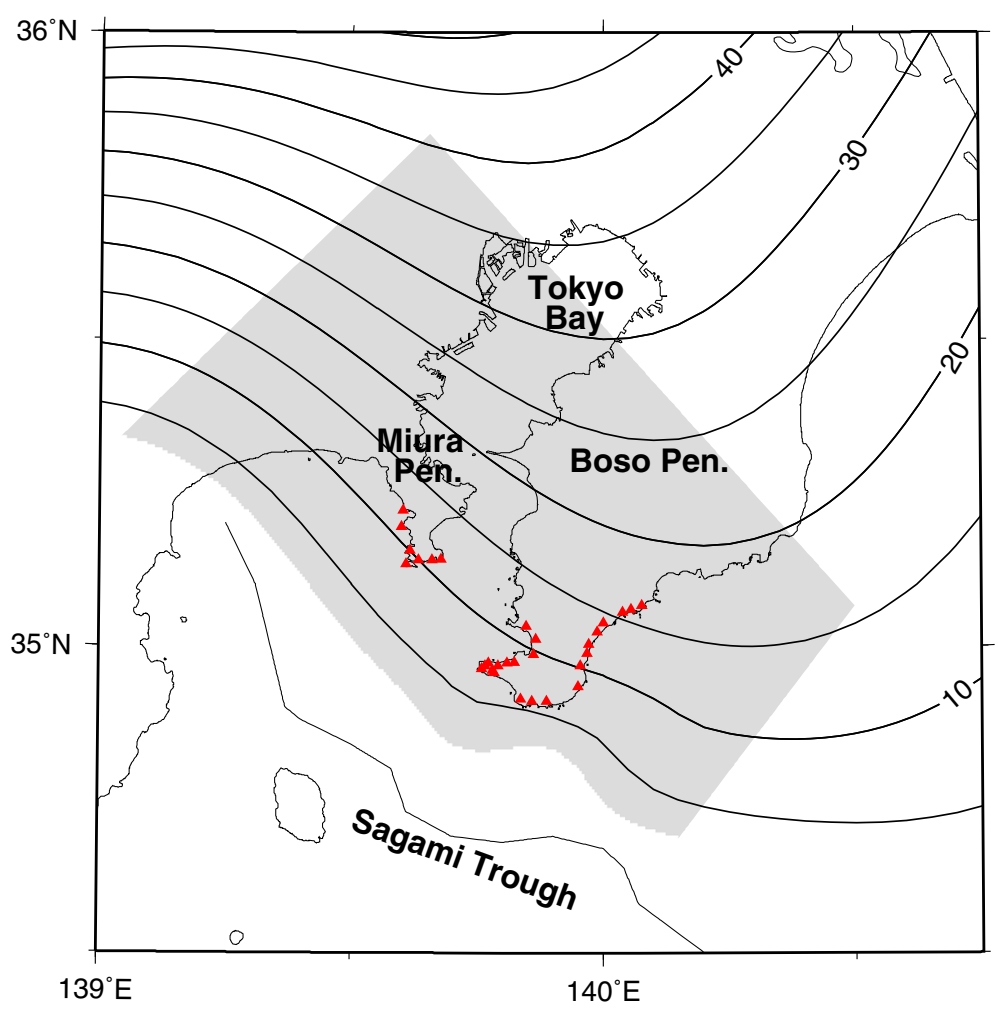

Fig. 4 Geometry of the plate interface and the model region. The geometry of the upper boundary surface of the Philippine Sea plate is shown by isodepth contours at the interval of $5 \mathrm{~km}$. The shaded area indicates the model region for the present analysis. The red triangles indicate observation sites

1960-1990, Ozawa et al. (1997) estimated the subsidence rates at Aburatsubo (site no. 3) and Mera (site no. 19) as $-3.05 \mathrm{~mm} /$ year and $-2.57 \mathrm{~mm} /$ year, respectively. We can calculate the average subsidence rates $R_{s}$ for 1963-1983 from Eq. (8) as

$$
\begin{aligned}
& R_{s}(\mathbf{x})=[\Delta z(\mathbf{x}, 1983)-\Delta z(\mathbf{x}, 1963)] / 20 \\
& =U_{s}(\mathbf{x}, \infty)-\frac{U_{G}(\mathbf{x}, \infty)}{T_{G}}-\frac{U_{T}(\mathbf{x}, \infty)}{T_{T}}+\frac{U_{G}(\mathbf{x}, 280)-U_{G}(\mathbf{x}, 260)}{20} \\
& +\frac{U_{T}(\mathbf{x}, 60)-U_{T}(\mathbf{x}, 40)}{20}
\end{aligned}
$$

In the right two columns of Table 2, we show the calculated subsidence rates together with estimation errors (standard deviations). If the calculated subsidence rates are much larger or smaller than the observed subsidence rates, we should exclude such a case from the list of reasonable models.

From these screening tests, we selected only three cases, case 350_4, case 350_5, and case 350_6, as reasonable models. Among them, case 350_4 $(T=350$ year, $n=4)$ is the best in the sense of least squares. This means that the recurrence interval of the Genroku-type events is about $350 \times 4=1400$ year.

Figure 5 shows the fault slip distribution of the 1703 Genroku event estimated in case 350_4 ( $T=$
350 year, $n=4 ; T_{G}=1400$ year) together with the estimation errors. The RMS of data fitting errors is about $0.17 \mathrm{~m}$, which is consistent with the estimated standard deviation of data errors $(\hat{\sigma}=0.23 \mathrm{~m})$ in Eq. (22). From Fig. 5a, we can see that the large slip $(>8 \mathrm{~m})$ area extends along the Sagami trough from the Miura peninsula to the southeast offing of the Boso peninsula, and the coseismic slip takes the maximum of $20 \mathrm{~m}$ at the southern tip of the Boso peninsula. The moment magnitude $(\mathrm{Mw})$ is calculated as $8.18 \pm 0.03$. As shown in Fig. 5b, the estimation errors are very large because of the sparse and uneven distribution of inaccurate data and the low dip-angle at the shallow part of the plate interface. For reference, we show the estimated fault slip distributions for case 300_3 ( $T=$ 300 year, $n=3 ; T_{G}=900$ year $)$ and case 400_5 $(T=400$ year, $n=5 ; T_{G}=2000$ year) in Fig. $6 \mathrm{a}$ and b, respectively. In either case, the RMS of data fitting errors is about $0.17 \mathrm{~m}$. The fault slip patterns are similar to case 350_4 in both cases. The maximum slip is about $24 \mathrm{~m}$ for case 300_3 and $20 \mathrm{~m}$ for case 400_5.

From the fault slip distribution in Fig. 5a, we can compute the coseismic vertical displacements of the 1703 Genroku event as shown in Fig. 7. According to Shishikura (2000b), historical records tell that the coseismic vertical displacements change from uplift in 
Table 2 Slip-deficit rates and subsidence rates $\left(M S L_{3}\right.$ kyr BP $\left.=0 \mathrm{~m}\right)$

\begin{tabular}{|c|c|c|c|c|c|c|}
\hline \multirow[t]{5}{*}{ Case } & \multicolumn{4}{|c|}{ Slip-deficit rate } & \multicolumn{2}{|c|}{ Subsidence rate } \\
\hline & \multirow{2}{*}{\multicolumn{2}{|c|}{$\begin{array}{l}\text { Miura } \\
\text { Site no. } 1\end{array}$}} & \multirow{2}{*}{\multicolumn{2}{|c|}{$\begin{array}{l}\text { Southernmost Boso } \\
\text { Site no. } 16\end{array}$}} & \multirow{4}{*}{$\begin{array}{l}\text { Aburatsubo } \\
\text { Site no. } 3 \\
\mathrm{R}_{\mathrm{S}} \\
\mathrm{mm} / \text { year }\end{array}$} & \multirow{4}{*}{$\begin{array}{l}\text { Mera } \\
\text { Site no. } 19 \\
\text { RS } \\
\text { mm/year }\end{array}$} \\
\hline & & & & & & \\
\hline & $\mathrm{S}_{\mathrm{G}}$ & $R_{d}$ & $S_{G}$ & $R_{d}$ & & \\
\hline & $\mathrm{m}$ & $\mathrm{cm} /$ year & $\mathrm{m}$ & $\mathrm{cm} /$ year & & \\
\hline 300_2 & $18 \pm 15$ & $4.3 \pm 2.5$ & $30 \pm 11$ & $6.0 \pm 1.8$ & $-3.41 \pm 1.07$ & $-11.31 \pm 1.07$ \\
\hline 300_3 & $16 \pm 11$ & $3.6 \pm 1.2$ & $24 \pm 9$ & $4.0 \pm 1.0$ & $-3.44 \pm 0.85$ & $-6.62 \pm 0.85$ \\
\hline $300 \_4$ & $14 \pm 9.5$ & $3.2 \pm 0.8$ & $21 \pm 7.5$ & $3.3 \pm 0.7$ & $-3.46 \pm 0.83$ & $-5.01 \pm 0.83$ \\
\hline $300 \_5$ & $13 \pm 9.5$ & $3.0 \pm 0.7$ & $20 \pm 7.5$ & $2.9 \pm 0.6$ & $-3.46 \pm 0.79$ & $-4.23 \pm 0.79$ \\
\hline $300 \_6$ & $14 \pm 9$ & $3.0 \pm 0.6$ & $20 \pm 7$ & $2.8 \pm 0.5$ & $-3.46 \pm 0.78$ & $-3.75 \pm 0.78$ \\
\hline 300_7 & $14 \pm 9$ & $3.0 \pm 0.5$ & $20 \pm 7$ & $2.7 \pm 0.4$ & $-3.46 \pm 0.77$ & $-3.43 \pm 0.77$ \\
\hline 350_2 & $13 \pm 12$ & $3.0 \pm 1.7$ & $25 \pm 10$ & $4.4 \pm 1.4$ & $-2.24 \pm 0.98$ & $-6.57 \pm 0.98$ \\
\hline 350_3 & $12 \pm 10$ & $2.7 \pm 1.0$ & $21 \pm 7.5$ & $3.1 \pm 0.7$ & $-2.50 \pm 0.86$ & $-3.74 \pm 0.86$ \\
\hline 350_4 & $12 \pm 9.5$ & $2.6 \pm 0.7$ & $19 \pm 7.5$ & $2.6 \pm 0.6$ & $-2.58 \pm 0.80$ & $-2.73 \pm 0.80$ \\
\hline 350_5 & $13 \pm 9$ & $2.6 \pm 0.6$ & $19 \pm 7$ & $2.5 \pm 0.5$ & $-2.63 \pm 0.78$ & $-2.18 \pm 0.78$ \\
\hline $350 \_6$ & $12 \pm 9$ & $2.5 \pm 0.5$ & $19 \pm 7$ & $2.3 \pm 0.4$ & $-2.66 \pm 0.77$ & $-1.85 \pm 0.77$ \\
\hline 400_2 & $12 \pm 12$ & $2.5 \pm 1.5$ & $23 \pm 9$ & $3.6 \pm 1.1$ & $-1.53 \pm 0.89$ & $-3.80 \pm 0.89$ \\
\hline 400_3 & $11 \pm 9.5$ & $2.3 \pm 0.8$ & $20 \pm 7.5$ & $2.7 \pm 0.6$ & $-1.86 \pm 0.83$ & $-1.86 \pm 0.83$ \\
\hline 400_4 & $12 \pm 9$ & $2.3 \pm 0.6$ & $19 \pm 7$ & $2.3 \pm 0.5$ & $-1.98 \pm 0.79$ & $-1.13 \pm 0.79$ \\
\hline $400 \_5$ & $11 \pm 9$ & $2.2 \pm 0.5$ & $18 \pm 7$ & $2.1 \pm 0.4$ & $-2.05 \pm 0.77$ & $-0.74 \pm 0.77$ \\
\hline 400_6 & $11 \pm 9$ & $2.1 \pm 0.4$ & $18 \pm 7$ & $2.0 \pm 0.4$ & $-2.09 \pm 0.76$ & $-0.50 \pm 0.76$ \\
\hline
\end{tabular}

Italicized data indicate that the relative plate velocity $(2.7 \mathrm{~cm} /$ year $)$ is included within the range of calculated slip-deficit rate \pm one standard deviation and that the observed subsidence rate $(-3.05 \mathrm{~mm} /$ year at Aburatsubo, $-2.57 \mathrm{~mm} /$ year at Mera) is included within the range of calculated subsidence rate \pm one standard deviation $S_{G}$ slip amount, $R_{d}$ slip-deficit rate, $R_{S}$ subsidence rate

south to subsidence in north at the points indicated by the solid triangles. Our result is consistent with the historical records along the east coast of the Boso peninsula, but not along the west coast. For the coseismic vertical displacements along the north coastline of the Sagami Bay, Shishikura (2003) reported the uplift less than $2 \mathrm{~m}$ at Oiso (indicated by the solid diamond), but Matsuda et al. (2014) recently reported that the uplift is less than $1 \mathrm{~m}$. Our result is about $0 \mathrm{~m}$.
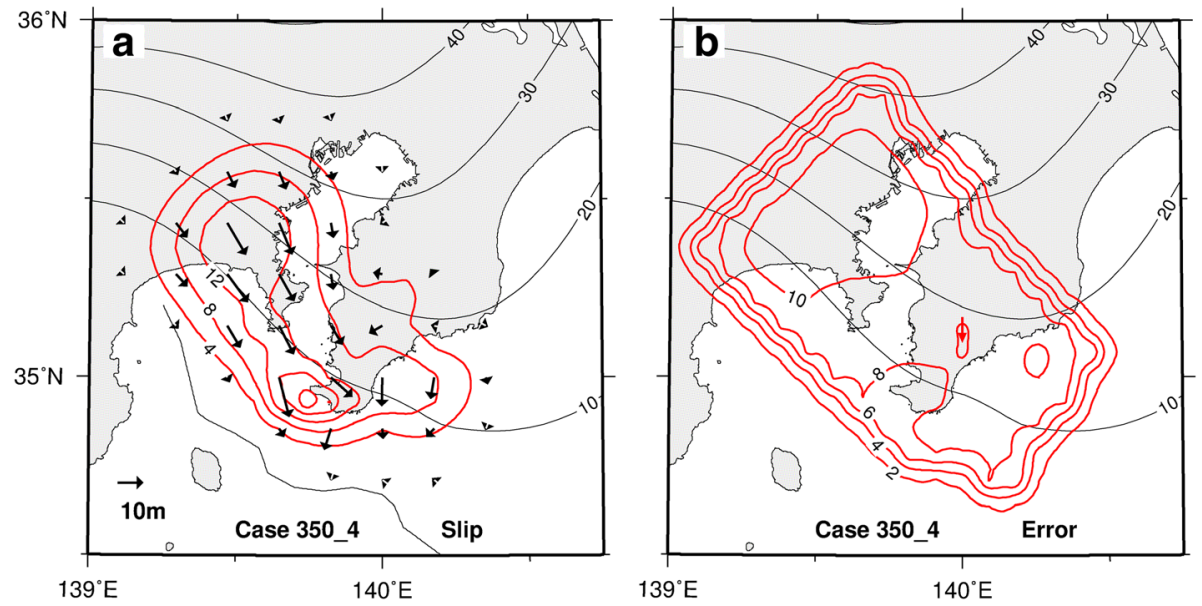

Fig. 5 Optimum fault-slip distribution of the Genroku event estimated from paleo-shoreline data. a Optimum fault-slip distribution of the 1703 Genroku event estimated in case 350_4 ( $T=350$ year, $n=4 ; T_{G}=1400$ year). The red contours and black arrows indicate the slip amounts and slip vectors, respectively. The contour interval is $4 \mathrm{~m}$. b Contour map of estimation errors at the interval of $2 \mathrm{~m}$. The red arrow indicates a hollow place 

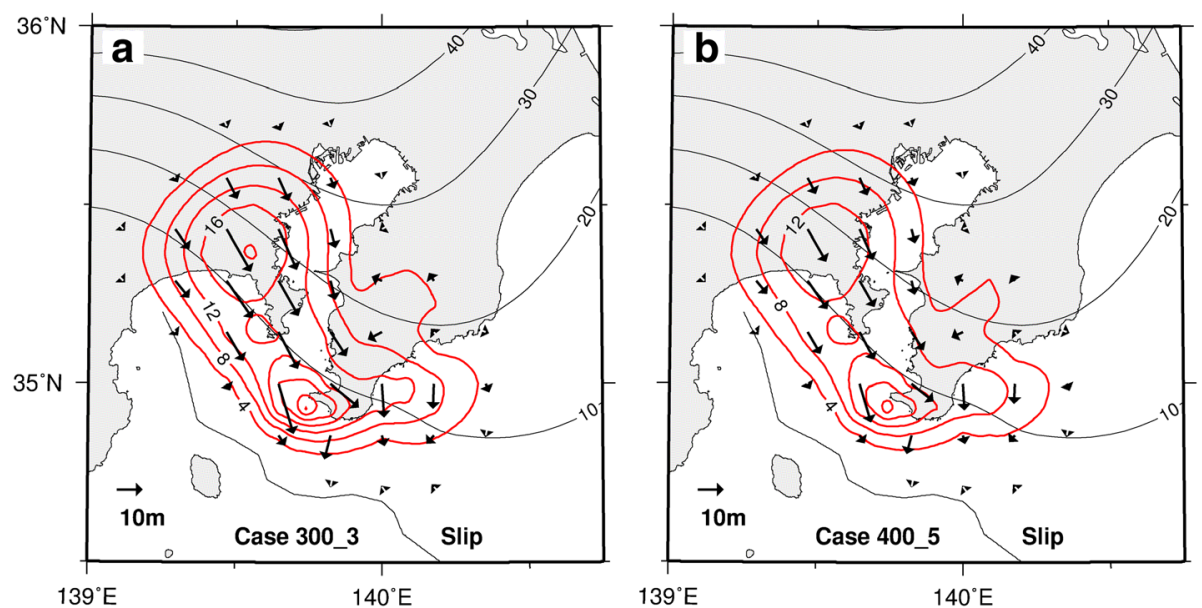

Fig. 6 Fault slip distributions of the Genroku event for case 300_3 and case 400_5. a Fault slip distribution estimated in case 300_3 ( $T=300$ year, $n=3 ; T_{G}=900$ year). $\mathbf{b}$ Fault slip distribution estimated in case 400_5 ( $T=400$ year, $n=5 ; T_{G}=2000$ year). The red contours and black arrows indicate the slip amounts and slip vectors, respectively

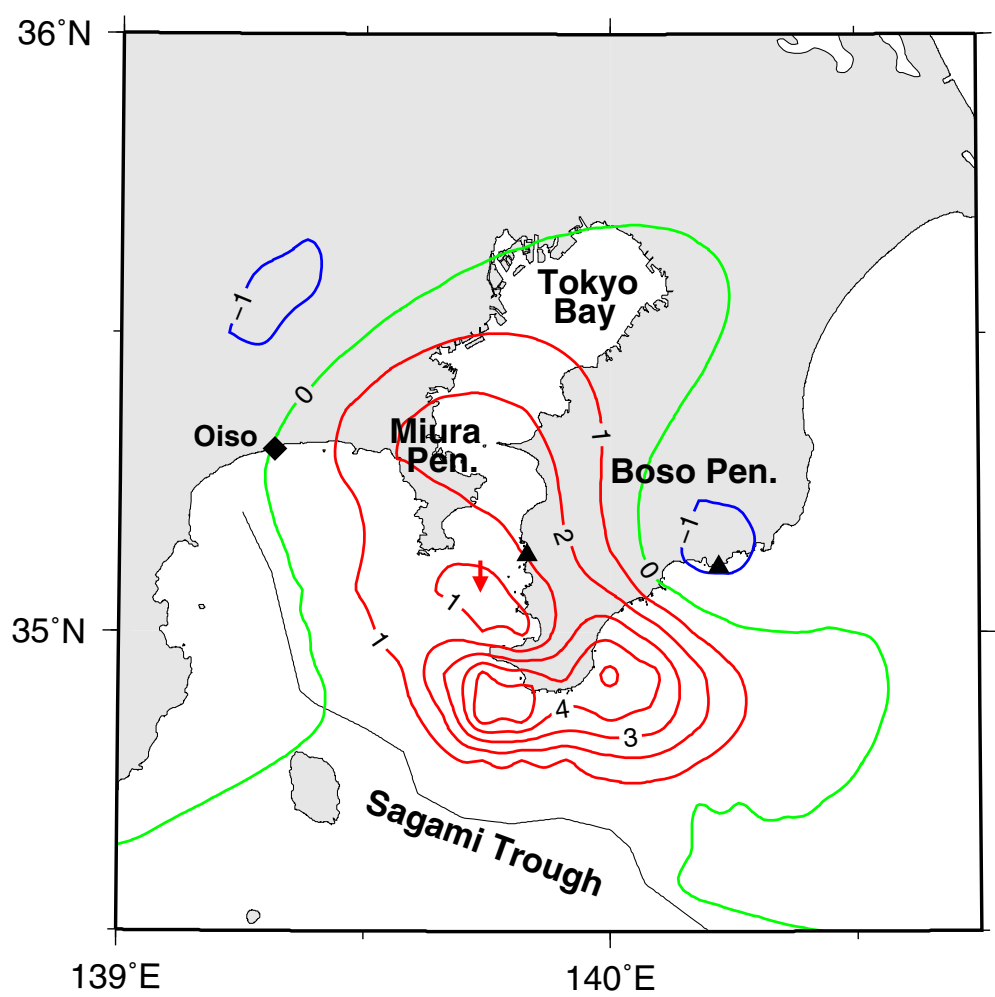

Fig. 7 Coseismic vertical displacements of the Genroku event computed from the optimum fault slip distribution. The vertical displacements were computed from the optimum fault slip distribution in Fig. 5a. The red, green, and blue contours indicate uplifts, neutral, and subsidence, respectively. The contour interval is $1 \mathrm{~m}$. The red arrow indicates a hollow place. The solid triangles indicate the change points from uplift to subsidence estimated from historical records (Shishikura 2000b). The solid diamond indicates the location of Oiso 
In Fig. 8, we examine each term of Eq. (24) in case 350_4. For the present heights of the Genroku terrace (the left side), the observed data (blue diamonds) are well explained by the computed values (red squares). The effects of steady plate subduction (the first term on the right side), which are indicated by yellow squares, are about $1 \mathrm{~m}$ uplift for 300 years (about $3 \mathrm{~mm} /$ year). The effects of steady slip deficit in the source region of interplate earthquakes (the second and third terms), which are indicated by light blue diamonds, are widely different place by place. The southernmost point (no. 19) is $3 \mathrm{~m}$ subsidence for 300 years, and the northern Miura (nos. 1 and 2) and northern Sotobo (no. 30) points are less than $1 \mathrm{~m}$ subsidence. The fourth term includes the coseismic, $U_{G}(\mathbf{x}, 0)$, and postseismic, $U_{G}(\mathbf{x}$, 295) $-U_{G}(\mathbf{x}, 0)$, displacements of the 1703 Genroku event, which are indicated by pink triangles and pink circles, respectively. The coseismic displacements of the 1703 Genroku event are 4-5 $\mathrm{m}$ at the southernmost Boso peninsula and rapidly decrease toward the northern points. The fifth term includes the coseismic and postseismic displacements of the 1923 Taisho event, the total of which is indicated by green triangles. The differences between the observed heights of the Genroku terrace and the estimated coseismic displacements, which are the interseismic total displacements indicated by crosses, are $0.5-1.5 \mathrm{~m}$ at the Miura area, $2-3 \mathrm{~m}$ at the Uchibo area, and 1-2 $\mathrm{m}$ at the Sotobo area. This means that the interseismic vertical movements are widely different place by place.

Figure 9 shows the computed temporal height changes of the Genroku terrace in case 350_4. From this figure, we can see a general trend: coseismic uplifts, postseismic slow uplifts due to viscoelastic stress relaxation in the asthenosphere (50-60 years after each event), and very slow subsidences due to steady increase of slip deficits. Figures 8 and 9 indicate that the postseismic and interseismic vertical movements are significantly different not only place by place but also in time. Therefore, we cannot simply assume a constant recovery rate (in time and space) to estimate coseismic displacements from paleo-shoreline data.

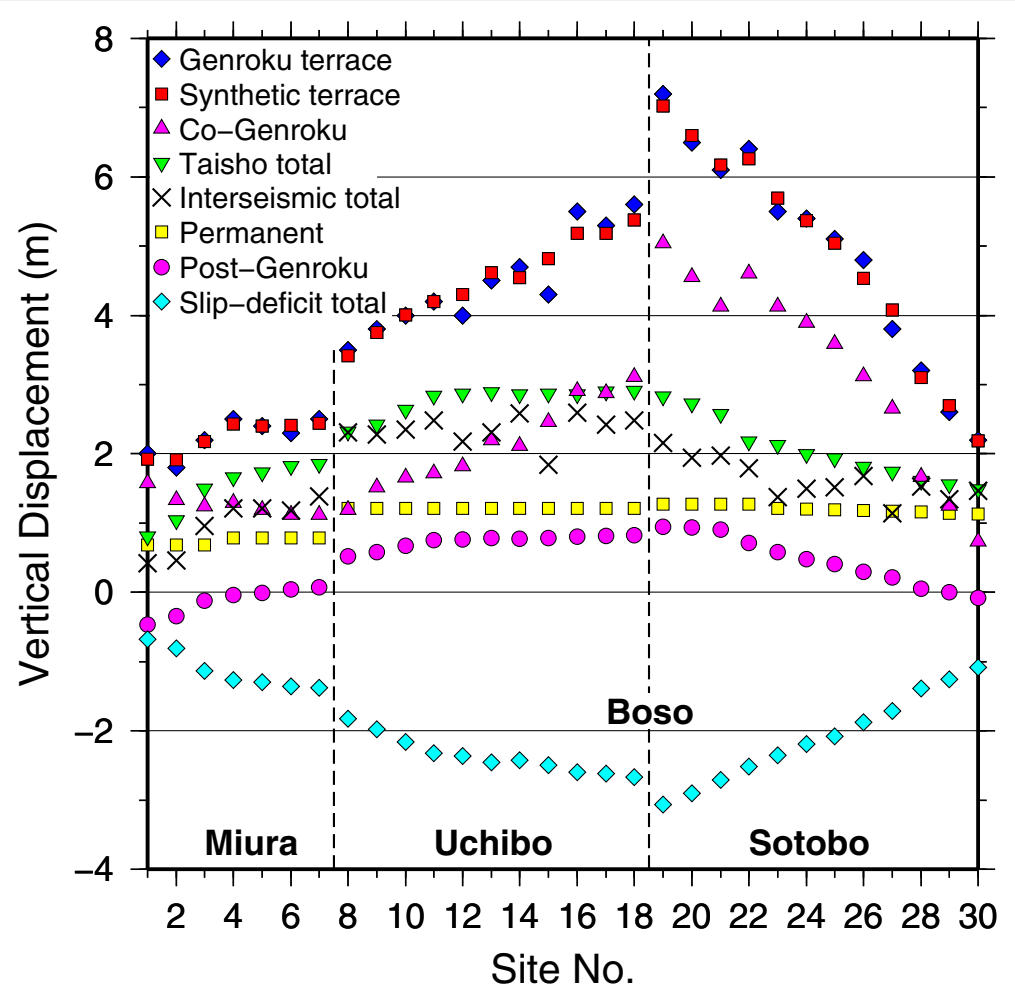

Fig. 8 Decomposition of Genroku-shoreline heights into individual effects. In this diagram, individual terms of Eq. (24) are evaluated for the optimum model in case 350_4. The blue diamonds indicate the height data of the Genroku paleo-shoreline (the left side of Eq. (24)). The red squares indicate the calculated heights for the optimum model. The explanations of the other symbols are as follows: pink triangles and pink circles: the computed coseismic vertical displacements of the 1703 Genroku event and the viscous responses of the 1703 Genroku event, respectively (the fourth term on the right side of Eq. (24)), green triangles: the effects of the 1923 Taisho event (the fifth term), yellow squares: the permanent displacements due to steady plate subduction for 295 years (the first term), light blue diamonds: the displacements due to steady slip deficit for 295 years (the second and third terms), and crosses: differences between the Genroku paleo-shoreline heights and the computed coseismic vertical displacements, which indicate that the interseismic vertical movements are much different place by place 


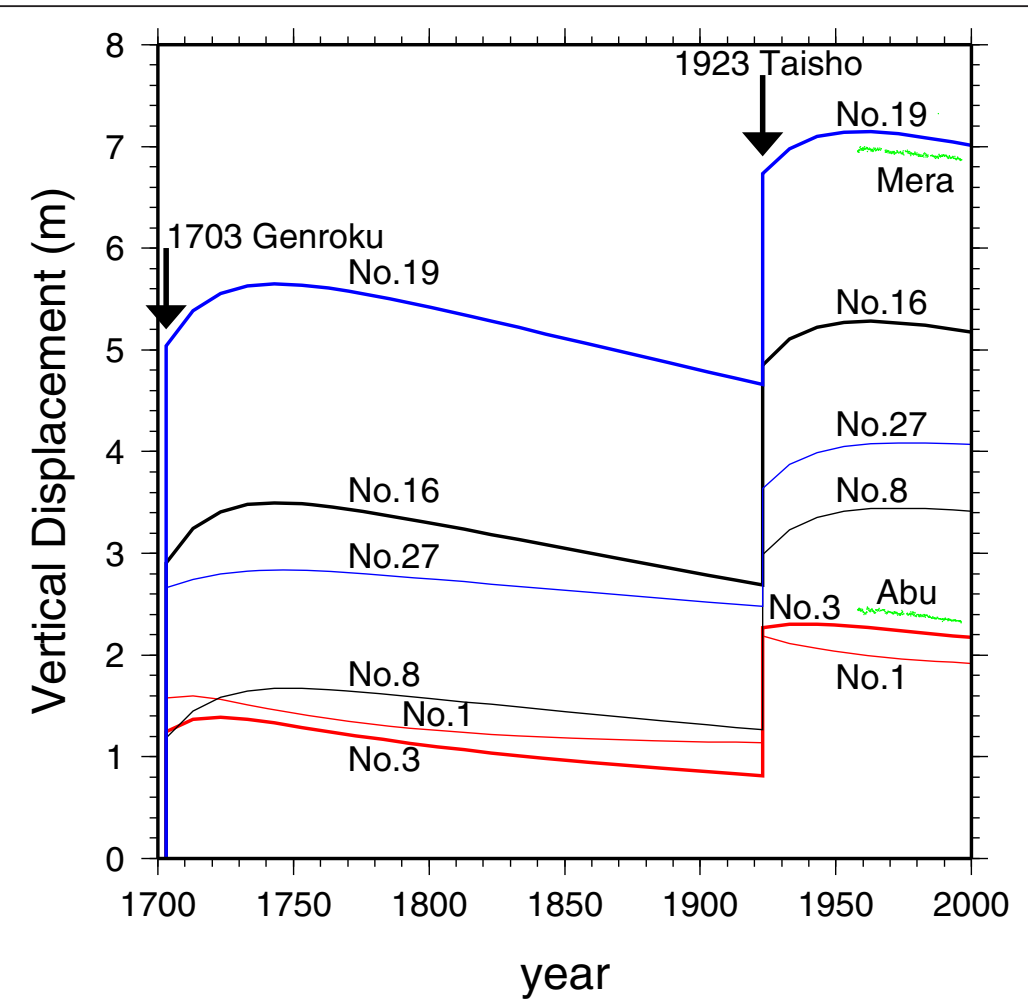

Fig. 9 Temporal height changes of the Genroku terrace. Temporal height changes of the Genroku terrace are computed in case 350_4. The red, black, and blue lines indicate the Miura, Uchibo, and Sotobo areas, respectively. The site numbers correspond to those in Fig. 3. Green dots indicate tide-gauge data from 1958 to 1996 (Ozawa et al. 1997). Abu denotes data on Aburatsubo (near no.3) and Mera denotes data on Mera (near no.19)

\section{Discussion}

We estimated the standard deviation of data errors, $\hat{\sigma}$ in Eq. (22), to be about $0.23 \mathrm{~m}$ in case 350_4. According to Shishikura (2000b, 2001), the maximum error of original data is about $1 \mathrm{~m}$. This suggests that the standard error of the original data is some dozen centimeters, which is consistent with the estimate of $\hat{\sigma}$ in our inversion analysis and also the RMS of data fitting errors $(0.17 \mathrm{~m})$ in case 350_4.

In the "Results" section, we estimated the fault slip distribution of the 1703 Genroku event from paleoshoreline data on the assumption that the mean sea level at $3 \mathrm{kyr} \mathrm{BP}$ relative to the present is $0 \mathrm{~m}$. From oxygen isotope records of deep-sea sediment, Siddall et al. (2003) reconstructed the history of sea-level changes over the past $470 \mathrm{kyr}$. According to their sea-level fluctuation curve, although its accuracy is not so high, the mean sea level at $3 \mathrm{kyr} \mathrm{BP}$ relative to the

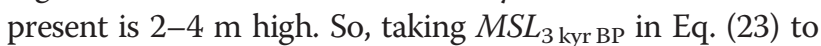
be $3 \mathrm{~m}$, we tried to re-estimate the fault slip distribution of the Genroku event in the same way as in the "Results" section. The results are summarized in Table 3. The fault slip patterns are very similar to the case of $M S L_{3 \mathrm{kyr} \mathrm{BP}}=0$, and the slip amounts increase slightly. The calculated subsidence rates for $M S L_{3 \mathrm{kyr} \mathrm{BP}}=3 \mathrm{~m}$ are larger than those for
$M S L_{3 \mathrm{kyr} \mathrm{BP}}=0$. In the case of $M S L_{3 \mathrm{kyr} \mathrm{BP}}=3 \mathrm{~m}$, the selected reasonable models are case 400_3 ( $T=$ 400 year, $n=3 ; T_{G}=1200$ year $)$ and case $400 \_4(T=$ 400 year, $n=4 ; T_{G}=1600$ year), though the best fit model is still case 350_4 for $M S L_{3 \mathrm{kyr} \mathrm{BP}}=0$. The recurrence interval of 1200-1600 years for the Genroku-type events is much shorter than the previous estimate of 2300 years based on the assumption that the Holocene marine terraces (Numa I-III) were formed by the Genroku-type events.

From basically the same data as we used, Kasahara et al. (1973), Matsuda et al. (1978), and Shishikura (2003) have proposed various composite fault models of the 1703 Genroku event. The Kasahara model consists of the fault model of the 1923 Taisho event by Ando (1971) and a NW-dipping, high-angle $\left(60^{\circ}\right)$ thrust fault located just south off the Boso peninsula. The Matsuda model is similar to the Kasahara model, but the northern one third of the Taisho event fault has been eliminated, because the coseismic displacements along the north coast of the Sagami Bay are not significant. The Shishikura model is also similar to the Kasahara model, but the high-angle thrust fault just south off the Boso peninsula has been replaced with a low-angle $\left(20^{\circ}\right)$ narrow thrust fault. From stratigraphic studies of sedimentary 
Table 3 Slip-deficit rates and subsidence rates $\left(M S L_{3}\right.$ kyr $\left.\mathrm{BP}=3 \mathrm{~m}\right)$

\begin{tabular}{|c|c|c|c|c|c|c|}
\hline \multirow[t]{5}{*}{ Case } & \multicolumn{4}{|c|}{ Slip-deficit rate } & \multicolumn{2}{|c|}{ Subsidence rate } \\
\hline & \multicolumn{2}{|l|}{ Miura } & \multicolumn{2}{|c|}{ Southernmost Boso } & \multirow{4}{*}{$\begin{array}{l}\text { Aburatsubo } \\
\text { Site no. } 3 \\
\text { Rs } \\
\text { mm/year }\end{array}$} & \multirow{4}{*}{$\begin{array}{l}\text { Mera } \\
\text { Site no. } 19 \\
\mathrm{R}_{\mathrm{S}} \\
\mathrm{mm} / \text { year }\end{array}$} \\
\hline & \multicolumn{2}{|l|}{ Site no. 1} & \multicolumn{2}{|c|}{ Site no. 16} & & \\
\hline & $S_{G}$ & $R_{d}$ & $S_{G}$ & $R_{d}$ & & \\
\hline & $\mathrm{m}$ & $\mathrm{cm} /$ year & $\mathrm{m}$ & $\mathrm{cm} /$ year & & \\
\hline 300_2 & $20 \pm 15$ & $4.7 \pm 2.5$ & $31 \pm 12$ & $6.2 \pm 1.9$ & $-5.39 \pm 1.07$ & $-13.26 \pm 1.07$ \\
\hline 300_3 & $17 \pm 12$ & $3.7 \pm 1.3$ & $24 \pm 9$ & $4.0 \pm 1.0$ & $-4.94 \pm 0.85$ & $-8.09 \pm 0.85$ \\
\hline $300 \_4$ & $15 \pm 10$ & $3.3 \pm 0.9$ & $22 \pm 7.5$ & $3.3 \pm 0.7$ & $-4.79 \pm 0.84$ & $-6.33 \pm 0.84$ \\
\hline $300 \_5$ & $15 \pm 9.5$ & $3.1 \pm 0.7$ & $21 \pm 7.5$ & $3.0 \pm 0.6$ & $-4.70 \pm 0.80$ & $-5.47 \pm 0.80$ \\
\hline $300 \_6$ & $15 \pm 9$ & $3.1 \pm 0.6$ & $20 \pm 7$ & $2.8 \pm 0.5$ & $-4.66 \pm 0.79$ & $-4.93 \pm 0.79$ \\
\hline $300 \_7$ & $15 \pm 9$ & $3.0 \pm 0.5$ & $20 \pm 7$ & $2.7 \pm 0.4$ & $-4.63 \pm 0.77$ & $-4.58 \pm 0.77$ \\
\hline 350_2 & $13 \pm 12$ & $3.0 \pm 1.7$ & $25 \pm 9.5$ & $4.4 \pm 1.4$ & $-3.98 \pm 0.99$ & $-8.28 \pm 0.99$ \\
\hline 350_3 & $13 \pm 11$ & $2.8 \pm 1.1$ & $22 \pm 8.5$ & $3.2 \pm 0.8$ & $-3.89 \pm 0.80$ & $-5.18 \pm 0.80$ \\
\hline $350 \_4$ & $12 \pm 9.5$ & $2.6 \pm 0.7$ & $20 \pm 7.5$ & $2.7 \pm 0.6$ & $-3.85 \pm 0.80$ & $-3.98 \pm 0.80$ \\
\hline 350_5 & $12 \pm 9$ & $2.5 \pm 0.6$ & $19 \pm 7$ & $2.5 \pm 0.5$ & $-3.84 \pm 0.79$ & $-3.37 \pm 0.79$ \\
\hline $350 \_6$ & $12 \pm 9$ & $2.5 \pm 0.5$ & $19 \pm 7$ & $2.3 \pm 0.4$ & $-3.83 \pm 0.77$ & $-3.01 \pm 0.77$ \\
\hline $400 \_2$ & $11 \pm 12$ & $2.4 \pm 1.4$ & $23 \pm 9.5$ & $3.6 \pm 1.2$ & $-3.12 \pm 0.89$ & $-5.36 \pm 0.89$ \\
\hline 400_3 & $11 \pm 9.5$ & $2.3 \pm 0.8$ & $19 \pm 7.5$ & $2.6 \pm 0.6$ & $-3.19 \pm 0.83$ & $-3.18 \pm 0.83$ \\
\hline $400 \_4$ & $11 \pm 9$ & $2.2 \pm 0.6$ & $19 \pm 7$ & $2.3 \pm 0.5$ & $-3.21 \pm 0.80$ & $-2.34 \pm 0.80$ \\
\hline 400_5 & $11 \pm 9$ & $2.2 \pm 0.5$ & $19 \pm 7$ & $2.2 \pm 0.4$ & $-3.22 \pm 0.77$ & $-1.90 \pm 0.77$ \\
\hline 400_6 & $11 \pm 9$ & $2.1 \pm 0.4$ & $18 \pm 7$ & $2.0 \pm 0.4$ & $-3.23 \pm 0.75$ & $-1.63 \pm 0.75$ \\
\hline
\end{tabular}

Legends are the same as in Table 2

basins in the offshore region adjacent to the Boso peninsula, Kimura et al. (2009) revealed that the outof-sequence thrusts have been inactive since at least 3.5 Myr BP. So the hisgh-angle thrust faulting just south off the Boso peninsula is not supported by observed data.

In order to make clear the difference in rupture area between the Taisho and Genroku events, we compare the fault slip distribution of the best fit model (case 350_4 for $M S L_{3 \mathrm{kyr} \mathrm{BP}}=0$ ) with the coseismic slip distribution of the 1923 Taisho event estimated by Matsu'ura et al. (2007) in Fig. 10. In both cases, the same model of plate interface geometry (Hashimoto et al. 2004) is used for the inversion analysis, and so the comparison is done directly. The estimated fault slip distribution for the Genroku event has large uncertainty at the western part of the model region (around Oiso and Odawara), because we did not use data at that area in the inversion analysis. Nevertheless, as shown in Fig. 7, the computed surface displacements accord with the report that the uplift is less than $1 \mathrm{~m}$ at Oiso (Matsuda et al. 2014). Therefore, the estimated fault slip distribution may be reliable even in that area. In other words, it is unlikely that large coseismic slip occurred in the western part of the model region at the Genroku event. From Fig. 10, we can see that three main rupture areas (asperities) are distributed on the plate interface along the Sagami trough. It is interesting that the northern two asperities were ruptured at the Taisho event, but the southern two asperities were ruptured at the Genroku event. The rupture of the Taisho event started from a northern point near Odawara and propagated to the south. On the other hand, the rupture of the Genroku event started from a southern point, although its exact location is not determined but guessed at the southern tip of the Boso peninsula from intensity distribution (Usami 1980) and propagated to the north. So we can say that the Taisho and Genroku events share the central rupture area.

In Fig. 11, we superpose the fault slip distribution of the Genroku event (yellow green contours) on the interseismic slip-deficit rate distribution (blue contours) estimated by Noda et al. (2013). From Figs. 10 and 11, we can see that the total rupture area of the Taisho and Genroku events almost agrees with the interseismic slipdeficit area extending along the Sagami trough except the Izu-Mainland collision zone. Our understandings obtained through the present study are as follows. On the plate interface beneath the southern Kanto region, there exist three asperities distributed along the Sagami trough. The slip deficit accumulated in these asperities is eventually released by the occurrence of the Taisho- or Genroku-type event. The magnitudes and recurrence 


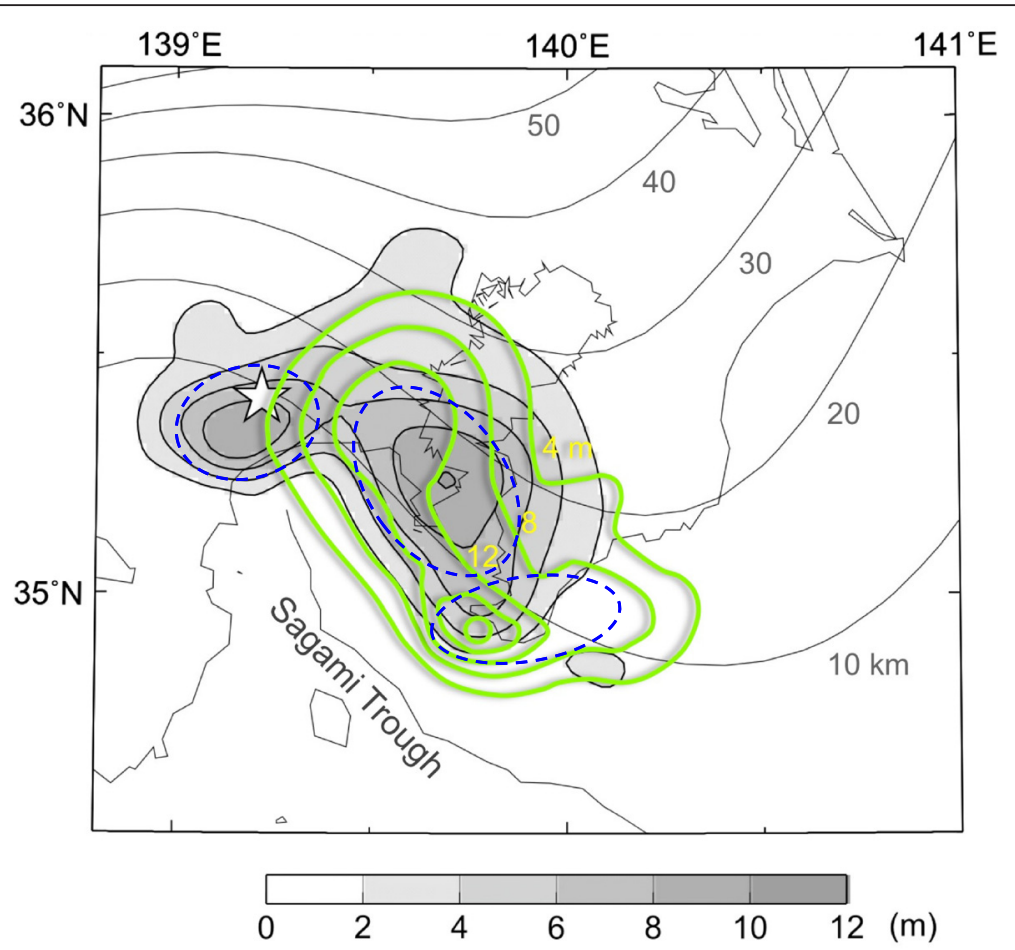

Fig. 10 Comparison of coseismic slip distribution between the Taisho and Genroku events. The gray scale contours represent the coseismic slip distribution of the 1923 Taisho event estimated from geodetic data (Matsu'ura et al. 2007). The superposed yellow green contours at the interval of $4 \mathrm{~m}$ represent the coseismic slip distribution of the 1703 Genroku event in Fig. 5a. The plate interface along the Sagami trough has three asperities (blue broken ellipses), and the central one is shared by the Taisho and Genroku events. The star indicates the epicenter of the Taisho event. The thin solid curves are the isodepth contours of the upper boundary surface for the descending Philippine Sea plate

intervals of these events may not be fixed because of nonlinear interaction between the three asperities.

Hatori et al. (1973) has reported tsunami heights due to the 1923 Taisho and the 1703 Genroku events, though the Genroku tsunami data have large uncertainty because many data come from documents and monuments for the event. The tsunami heights are similar for both events along the Sagami Bay coast and the Uchibo coast, but not along the Sotobo coast. The Genroku event generated much higher tsunami along the Sotobo coast in comparison with the Taisho event. This indicates that the Genroku event caused large seafloor uplift southeast off the Boso peninsula, which is consistent with our results (Fig. 7). Satake et al. (2008) computed tsunami heights on the Uchibo and Sotobo coasts and tsunami inundation on the Kujukuri coast (north of the Sotobo coast) for various composite fault models of the Genroku event, including the previously mentioned three representative models, namely, the Kasahara model, the Matsuda model, and the Shishikura model. According to their simulation results, the Kasahara model and the Shishikura model well explain tsunami height data along both the Uchibo and Sotobo coasts. As has been mentioned, the main body of the Shishikura model is similar to the Kasahara model. In the Shishikura model, to explain tsunami inundation data on the Kujukuri coast, an additional fault southeast off the Boso peninsula was introduced, though the existence of such a fault has not been confirmed. From the extent of seafloor uplift area (Fig. 7), our fault-slip model (case 350_4) would be able to totally explain the tsunami height data and the tsunami inundation data, but it is a future research task for us.

\section{Conclusions}

We developed an inversion method to estimate fault slip distribution of repeated interplate earthquakes from paleo-shoreline data on the idea of deformation cycles associated with subduction-zone earthquakes. By applying the inversion method to the present heights of the Genroku and Holocene marine terraces developed along the coasts of the Boso and Miura peninsulas, we estimated the fault slip distribution of the 1703 Genroku earthquake as follows. The source region extends along the Sagami trough from the Miura peninsula to the offing of the southern Boso peninsula, which covers the southern two thirds of the source region of the 1923 Kanto earthquake. The coseismic slip takes the maximum of $20 \mathrm{~m}$ at the southern tip of the Boso peninsula, 


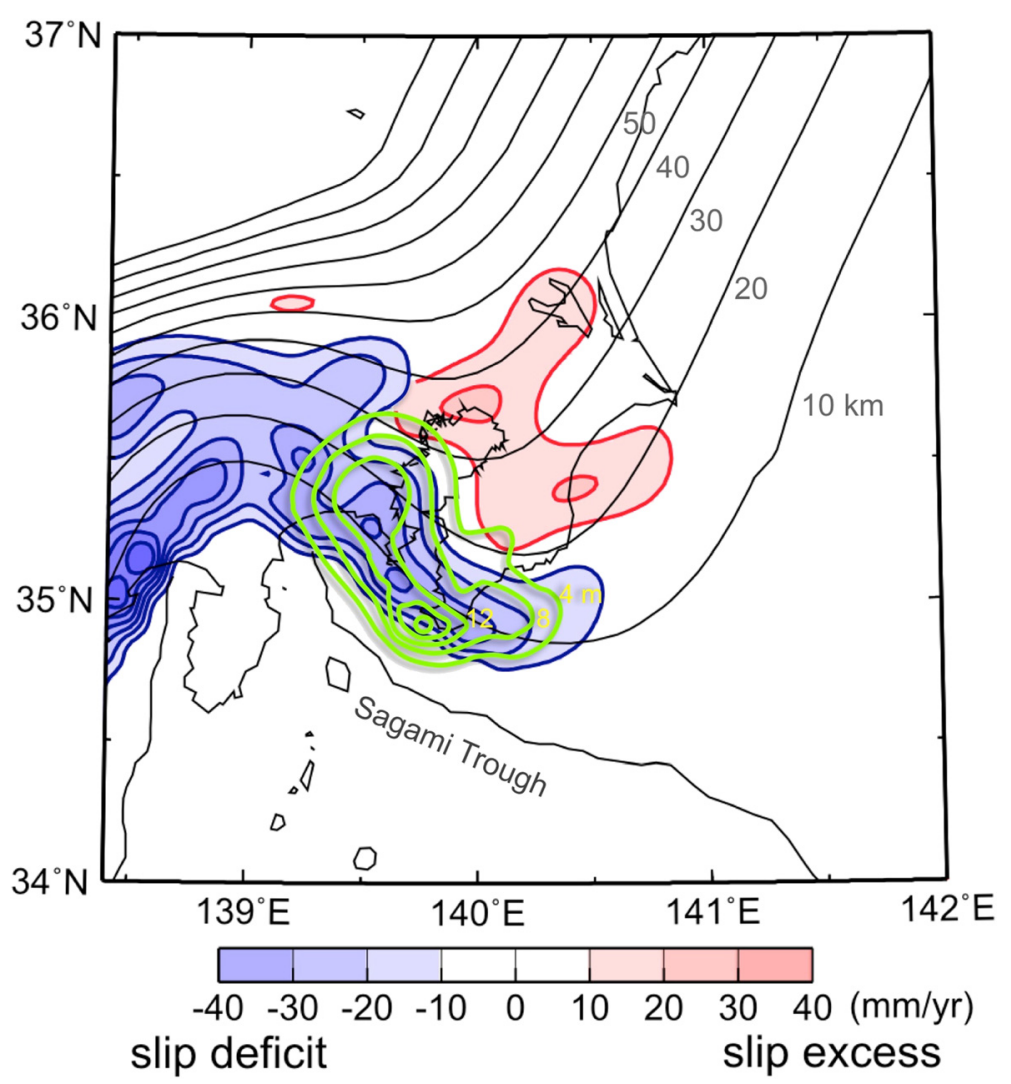

Fig. 11 Comparison of the coseismic slip distribution of the Genroku event with the interseismic slip-deficit rate distribution. The blue and red scale contours represent the interseismic slip-deficit and slip-excess rate distribution, respectively, estimated from GPS data (Noda et al. 2013). The superposed yellow green contours at the interval of $4 \mathrm{~m}$ represent the coseismic slip distribution of the 1703 Genroku event in Fig. 5a. The total rupture area of the Taisho and Genroku events (Fig. 10) almost agrees with the interseismic slip-deficit area extending along the Sagami trough except the Izu-Mainland collision zone. The thin solid curves are the isodepth contours of the upper boundary surface for the descending Philippine Sea plate

and the moment magnitude $(\mathrm{Mw})$ is calculated as 8.2. From the interseismic slip-deficit rates at the plate interface obtained by GPS data inversion, assuming that the total slip deficit is compensated by coseismic slip, we can roughly estimate the average recurrence interval as 350 years for large interplate events of any type and 1400 years for the Genroku-type events.

\section{Competing interests}

The authors declare that they have no competing interests.

\section{Authors' contributions}

TS and MM conceived this project, managed the grant by JSPS, and prepared the manuscript. TS and $\mathrm{HH}$ performed the calculations. TM and KE collected the paleo-shoreline data with the grant by JSPS. TM checked the reliability of the published data. MM and AN provided the digital data of the slip distribution for the 1923 Taisho event and a new concept about marine terrace development. NT collected the data of the plate interface geometry. TI conducted the Special Project for Earthquake Disaster Mitigation in Tokyo Metropolitan Area and provided many suggestions from the geological point of view. All authors read and approved the final manuscript.

\section{Acknowledgements}

We thank Dr. R S Matsu'ura and Dr. A Hashima for their useful comments. Dr. C Hashimoto provided the digital data of the plate boundary model
CAMP. Figures were prepared with the use of Generic Mapping Tool (Wessel and Smith 1998). This work was supported by the JSPS (Grantsin-Aid for Scientific Research, 17540390 and 23300336) and the Special Project for Earthquake Disaster Mitigation in Tokyo Metropolitan Area.

\section{Author details}

${ }^{1}$ Graduate School of Science, Chiba University, 1-33 Yayoi-cho, Inage-ku, Chiba 263-8522, Japan. ${ }^{2}$ Teikyo Heisei University, Tokyo, Japan. ${ }^{3}$ Kozo Keikaku Engineering Inc, Tokyo, Japan. ${ }^{4}$ Institute of Statistical Mathematics,

Tachikawa, Japan.

Received: 12 June 2015 Accepted: 21 January 2016

Published online: 09 February 2016

\section{References}

Akaike H (1980) Likelihood and the Bayes procedure. In: Bernardo JM, DeGroot MH, Lindley DV, Smith AFM (eds) Bayesian statistics. University Press, Valencia

Ando M (1971) A fault-origin model of the great Kanto earthquake of 1923 as deduced from geodetic data. Bull Earthq Res Inst, Univ Tokyo 49:19-32

DeMets CR, Gordon G, Argus DF, Stein S (1994) Effect of recent revisions to the geomagnetic reversal time scale on estimates of current plate motions. Geophys Res Lett 21:2191-2194

Endo K, Miyauchi T (2011) Reexamination in ages and altitudes of Holocene emergent coastal geomorphology associated with seismotectonics along the Sagami Trough, Japan (in Japanese)., JSAF 2011 Fall Meeting P-06 
Fukahata Y, Honsho C, Matsu'ura M (1996) Crustal movements on Shikoku, southwestern Japan, inferred from inversion analysis of levelling data using ABIC. Tectonophys 257:239-252

Hashimoto C, Fukui K, Matsu'ura M (2004) 3-D modelling of plate interfaces and numerical simulation of long-term crustal deformation in and around Japan. Pure Appl Geophys 161:2053-2068

Hatori T, Aida I, Kajiura K (1973) Tsunamis in the south Kanto district (in Japanese). In: Publications for the 50th Anniversary of the Great Kanto Earthquake, 1923. Earthquake Res Inst, Univ Tokyo, Tokyo, pp 57-66

Imamura A (1925) Change of the coast line in Boso peninsula (in Japanese). Report of the Imperial Earthquake Investigation Committee 100:91-93

Kaizuka S (1987) Quaternary crustal movements in Kanto (in Japanese with English abstract), Japan. J Geography 96(4):51-68

Kasahara K, Yamada J, Ando M (1973) Crustal movements in the southern Kanto district, and a related working hypothesis (in Japanese). In: Publications for the 50th Anniversary of the Great Kanto Earthquake, 1923. Earthq Res Inst Univ Tokyo, Tokyo, pp 103-116

Kimura H, Kasahara K, Takeda T (2009) Subduction process of the Philippine Sea plate off the Kanto district, central Japan, as revealed by plate structure and repeating earthquakes. Tectonophysics 472:18-27

Kobayashi R, Koketsu K (2005) Source process of the 1923 Kanto earthquake inferred from historical geodetic, teleseismic, and strong motion data. Earth Planets Space 57:261-270

Koike K, Machida H (2001) Atlas of Quaternary marine terraces in the Japanese islands (in Japanese). University of Tokyo Press, Tokyo

Kumaki Y (1982) Holocene terraces and tectonic movements in Miura Peninsula (in Japanese). Kokudochiriin Jiho (Geographical Survey Institute Journal) 54:41-49

Matsu'ura M, Iwasaki T (1983) Study on coseismic and postseismic crustal movements associated with the 1923 Kanto earthquake. Tectonophysics 97:201-215

Matsu'ura M, Sato T (1989) A dislocation model for the earthquake cycle at convergent plate boundaries. Geophys J Int 96(1):23-32

Matsu'ura M, Iwasaki T, Suzuki Y, Sato R (1980) Statical and dynamical study on faulting mechanism of the 1923 Kanto earthquake. J Phys Earth 28:119-143

Matsu'ura M, Noda A, Fukahata Y (2007) Geodetic data inversion based on Bayesian formulation with direct and indirect prior information. Geophys J Int 171(3):1342-1351

Matsuda T, Ota Y, Ando M, Yonekura N (1978) Fault mechanism and recurrence time of major earthquakes in southern Kanto district, Japan, as deduced from coastal terrace data. Geol Soc Am Bull 89:1610-1618

Matsuda T, Mizumoto T, Tajikara M, Matsu'ura RS (2014) Was the Oiso coast uplifted in time of the 1703 Genroku earthquake? - discussion on the marine terrace - (in Japanese). Zisin ser 2(67):35-39

Nakata T, Koba M, Imaizumi T, Jo WR, Matsumoto H, Suganuma T (1980) Holocene marine terraces and seismic crustal movements in the southern part of Boso peninsula, Kanto, Japan (in Japanese with English abstract). Geogr Rev Japan 53-2:29-44

Namegaya Y, Satake K, Shishikura M (2011) Fault models of the 1703 Genroku and 1923 Taisho Kanto earthquakes inferred from coastal movements in the southern Kanto area (in Japanese with English abstract). Annual Report on Active Fault and Paleoeathquake Researches 11:107-120

Noda A, Hashimoto C, Fukahata Y, Matsu'ura M (2013) Interseismic GPS strain data inversion to estimate slip-deficit rates at plate interfaces: application to the Kanto region, central Japan. Geophys J Int 193:61-77. doi:10.1093/gji/ggs129

Noda A, Miyauchi T, Sato T, Matsu'ura M (2015) Modeling and simulation for the development of Holocene marine terraces in the Boso peninsula., Abstracts of Japan Geoscience Union 2015 Annual Meeting S-CG57

Ozawa S, Hashimoto M, Tada T (1997) Vertical crustal movements in the coastal areas of Japan estimated from tidal observations. Bull Geogr Survey Inst 43: $1-21$

Satake K, Shishikura M, Namegaya Y, Fuji R, Takeuchi H (2008) Fault models of the Genroku (1703) Kanto earthquake and tsunamis along the eastern coast of Boso peninsula (in Japanese with English abstract). Historical Earthquake 23:81-90

Sato T, Matsu'ura M (1988) A kinematic model for deformation of the lithosphere at subduction zones. J Geophys Res 93:6410-6418

Shimazaki K, Nakata T (1980) Time-predictable recurrence model for large earthquakes. Geophys Res Lett 7(4):279-282
Shimazaki K, Kim HY, Chiba T, Satake K (2011) Geological evidence of recurrent great Kanto earthquakes at the Miura Peninsula, Japan. J Geophys Res 116, B12408. doi:10.1029/2011JB008639

Shishikura M (2000a) Holocene seismotectonics in the southern part of the Boso peninsula, central Japan, analyzing height distribution and ages of emerged shoreline topography., Ph D thesis, Graduate School of Natural Science Chiba University

Shishikura M (2000b) Coseismic vertical displacement in the Boso Peninsula during the 1703 Genroku Kanto earthquake, deduced from emerged shoreline topography (in Japanese with English abstract). Historical Earhquakes 16:113-122

Shishikura M (2001) Crustal movements in the Boso peninsula from the analysis of height distribution of the highest Holocene paleo-shoreline (in Japanese with English abstract). Annual Report on Active Fault and Paleoeathquake Researches 1:273-285

Shishikura M (2003) Cycle of interplate earthquake along the Sagami Trough, deduced from tectonic geomorphology (in Japanese with English abstract). Bull Earthq Res Inst, Univ Tokyo 78:245-254

Shishikura M, Echigo T (2001) Coseimic vertical displacement during the 1703 Genroku Kanto earthquake in the southern part of the Miura Peninsula, analyzing height distribution of emerged wave-cut benches and fossilized sessile assemblages (in Japanese with English abstract). Historical Earthquake 17:32-38

Siddall M, Rohling EJ, Almogl-Labin A, Hemleben C, Melschner D, Schmelzer I, Smeed DA (2003) Sea-level fluctuations during the last glacial cycle. Nature 423:853-858. doi:10.1038/nature01690

Thatcher W (1984) The earthquake deformation cycle at the Nankai Trough, southwest Japan. J Geophys Res 89:3087-3101

Tsumura N, Komada N, Sano J, Kikuchi S, Yamamoto S, Ito T, Sato T, Miyauchi T, Kawamura T, Shishikura M, Abe S, Sato H, Kawanaka T, Suda S, Higashinaka M, Ikawa T (2009) A bump on the upper surface of the Philippine Sea plate beneath the Boso peninsula, Japan inferred from seismic reflection surveys: a possible asperity of the 1703 Genroku earthquake. Tectonophysics 472:39-50

Umitsu M (1991) Holocene sea-level changes and coastal evolution in Japan. The Quaternary Research 30(2):187-196

Usami T (1980) Intensity distribution of the Genroku earthquake of Dec. 31, 1703 (in Japanese). Report of the Coordinating Committee for Earthquake Prediction 24(7-2):248-250

Utsu T (1999) Seismicity studies: a comprehensive review (in Japanese). University of Tokyo Press, Tokyo

Wessel P, Smith WHF (1998) New, improved version of the generic mapping tools released. EOS Trans AGU 79:579

Yabuki T, Matsu'ura M (1992) Geodetic data inversion using a Bayesian information criterion for spatial distribution of fault slip. Geophys J Int 109(2): $363-375$

\section{Submit your manuscript to a SpringerOpen ${ }^{\circ}$ journal and benefit from:}

- Convenient online submission

- Rigorous peer review

- Immediate publication on acceptance

- Open access: articles freely available online

- High visibility within the field

- Retaining the copyright to your article

Submit your next manuscript at springeropen.com 